\title{
Magnetic Nanoconjugated Teicoplanin: A Novel Tool for Bacterial Infection Site Targeting
}

\begin{abstract}
Ilaria Armenia, Giorgia Letizia Marcone, Francesca Berini, Viviana Teresa Orlandi, Cristina Pirrone, Eleonora Martegani, Rosalba Gornati, Giovanni Bernardini and Flavia Marinelli*
\end{abstract}

Department of Biotechnology and Life Sciences, University of Insubria, Varese, Italy

Nanoconjugated antibiotics can be regarded as next-generation drugs as they possess remarkable potential to overcome multidrug resistance in pathogenic bacteria. Iron oxide nanoparticles (IONPs) have been extensively used in the biomedical field because of their biocompatibility and magnetic properties. More recently, IONPs have been investigated as potential nanocarriers for antibiotics to be magnetically directed to/recovered from infection sites. Here, we conjugated the "last-resort" glycopeptide antibiotic teicoplanin to IONPs after surface functionalization with (3-aminopropyl) triethoxysilane (APTES).

OPEN ACCESS

Edited by:

Bingyun Li,

West Virginia University, United States

Reviewed by:

Fintan Thomas Moriarty, AO Research Institute, Switzerland Shuilin Wu,

Tianjin University, China

${ }^{*}$ Correspondence: Flavia Marinelli

flavia.marinelli@uninsubria.it

Specialty section:

This article was submitted to Antimicrobials, Resistance

and Chemotherapy,

a section of the journal

Frontiers in Microbiology

Received: 29 June 2018 Accepted: 05 September 2018 Published: 17 October 2018

Citation:

Armenia I, Marcone GL, Berini F, Orlandi VT, Pirrone C, Martegani E,

Gornati R, Bernardini $G$ and

Marinelli $F$ (2018) Magnetic Nanoconjugated Teicoplanin: A Novel

Tool for Bacterial Infection Site

Targeting. Front. Microbiol. 9:2270.

doi: 10.3389/fmicb.2018.02270
Classical microbiological methods and fluorescence and electron microscopy analysis were used to compare antimicrobial activity and surface interactions of naked IONPs, amino-functionalized NPS (NP-APTES), and nanoconjugated teicoplanin (NP-TEICO) with non-conjugated teicoplanin. As bacterial models, differently resistant strains of three Gram-positive bacteria (Staphylococcus aureus, Enterococcus faecalis, and Bacillus subtilis) and a Gram-negative representative (Escherichia coli) were used. The results indicated that teicoplanin conjugation conferred a valuable and prolonged antimicrobial activity to IONPs toward Gram-positive bacteria. No antimicrobial activity was detected using NP-TEICO toward the Gram-negative E. coli. Although IONPs and NP-APTES showed only insignificant antimicrobial activity in comparison to NP-TEICO, our data indicate that they might establish diverse interaction patterns at bacterial surfaces. Sensitivity of bacteria to NPs varied according to the surface provided by the bacteria and it was species specific. In addition, conjugation of teicoplanin improved the cytocompatibility of IONPs toward two human cell lines. Finally, NP-TEICO inhibited the formation of $S$. aureus biofilm, conserving the activity of non-conjugated teicoplanin versus planktonic cells and improving it toward adherent cells.

Keywords: antibiotic resistance, iron oxide nanoparticles, glycopeptide antibiotics, antimicrobial activity, teicoplanin, Staphylococcus aureus biofilm

\section{INTRODUCTION}

According to a recent survey of the World Health Organization (WHO, 2017), antibiotic resistance represents one of the greatest threats to global health today and contributes significantly to longer hospital permanence, higher medical costs, and increased mortality. At least 700,000 people die annually because of infections caused by resistant bacteria. This number is predicted to increase up 
to 10 million by 2050 and is consequentially associated with a social and economic burden. This public health threat is exacerbated by the paucity of novel antibiotics expected to enter clinical use in the near future (Fedorenko et al., 2015). A corollary to acute illness is the increased number of chronic bacterial infections due to the prevalence of biofilm colonization (Arciola et al., 2018). Currently, medical devicerelated infections account for more than $60 \%$ of all the hospitalacquired infections in the United States (Weiner et al., 2016). Biofilms are complex, three-dimensional bacterial communities living in a self-produced extracellular matrix. The biofilmforming bacteria survive better than their free-living (planktonic) counterparts in hostile environments; they are 10 to 100 times less susceptible to antimicrobial agents and are protected against the host immune system, making the treatment of these infections quite challenging (Davis, 2003; Venkatesan et al., 2015).

One promising approach in the field of antimicrobial therapy is the use of nanotechnology-tailored agents for preventing and treating infections caused by resistant bacteria. Unique and well-defined features distinguish nanoparticles (NPs) from their bulk counterparts, such as large surface area-to-volume ratio and dimensions that are comparable to those of biomolecules, effectively providing a platform with a high number of functional sites and possible interactions with bacterial cells and biofilms. Of all the NPs tested for antimicrobial activity thus far, silver NPs (AgNPs) have been studied most intensively (Natan and Banin, 2017). Although researchers have widely agreed that the broad-spectrum antibacterial activity of AgNPs can be predominantly ascribed to the release of $\mathrm{Ag}$ ions, AgNPs demonstrate unique properties because they adhere to the bacterial surface, altering membrane properties and thus delivering Ag ions more effectively to the bacterial cytoplasm and membrane (Durán et al., 2016). Consequently, the antibacterial effect of AgNPs is observed at concentrations with a 10fold lower magnitude than those used for bulk Ag ions. The antibacterial activity of AgNPs is reported to be mediated by a multiplicity of still-not-completely understood mechanisms following their interaction with the bacterial surface, which act in parallel (i.e., oxidative stress, membrane depolarization, and protein and DNA interaction), thus explaining why bacterial resistance does not easily arise (Hajipour et al., 2012; Natan and Banin, 2017; Baranwal et al., 2018). Very recent studies (Xiang et al., 2017; Xie et al., 2017, 2018) show that the antibacterial activity of AgNPs may be successfully exploited in preparing nanocomposite materials to be used as antibacterial coatings of titanium-based metallic implants and poly(ether ether ketone) medical devices, which are both widely employed in dentistry and orthopedic applications. Entrapping AgNPs in graphene oxide nanosheets wrapped with a thin layer of collagen (Xie et al., 2017), in hybrid polydopamine/graphene oxide coatings (Xie et al., 2018), or in biocompatible polymers such as poly(lactic-coglycolic) acid (Xiang et al., 2017) endows medical implants with a long-lasting self-antibacterial activity. In vivo studies using these innovative coatings in animal models confirm that combining the unique properties of different nanomaterials prevents bacterial infection and provides a good cytocompatibility of the medical devices (Xie et al., 2017, 2018).
A synergic, but as yet less exploited strategy when developing nano-based antimicrobial agents involves using NPs as nanocarriers for antibiotics, taking advantage of the high surface-to-volume ratio platform that they offer for attaching a large number of molecules. The advantages of using NPs in this way depend on the nature of both the NPs and the drugs under consideration, as recently reviewed (Natan and Banin, 2017). These advantages might include (i) protecting the nanoconjugated drug from degradation and oxidation; (ii) increasing drug solubility, antimicrobial activity, and biodistribution; (iii) delivering the antibiotic to the site of the infection; and (iv) enhancing drug penetration into biofilms, facilitating the killing of encased bacteria. As antibiotic nanocarriers, iron oxide nanoparticles (IONPs) have recently attracted increased interest thanks to their unique magnetic properties (Dinali et al., 2017). In fact, IONPs can be guided by an external magnetic field to a targeted organ/biofilm and specifically localized at the site of infection (Wu et al., 2015; Stepien et al., 2018). In addition, IONPs are easily produced and functionalized, and they possess a high drug-loading capacity, low cell toxicity, and high biocompatibility (Ali et al., 2016; Dinali et al., 2017). In the last decade, relatively few studies have investigated the potential of surface-modified IONPs as antibacterial agents in depth. Core-shell $\mathrm{Fe}_{3} \mathrm{O}_{4}$-AgNPs were tested as antimicrobial agents against Gram-positive and Gramnegative bacteria where the silver shell was responsible for antimicrobial action (Chudasama et al., 2009). Biocompatible polyvinyl alcohol-coated IONPs were used in biomedical applications and reported to be active against Staphylococcus aureus in a dose-dependent manner (Tran et al., 2010). Similarly, chitosan-coated IONPs were shown to have a higher antimicrobial activity than naked IONPs due to the positive surface potential, which interacted better with negatively charged bacterial cell surfaces (Arakha et al., 2015a). According to other authors (Huang et al., 2010; Ebrahiminezhad et al., 2014), IONP surface functionalization with (3-aminopropyl) triethoxysilane (APTES) elicited an antimicrobial effect by creating a high density of amino groups, which could interact with negatively charged sites on the bacterial cells through electrostatic interactions. The well-developed surface chemistry of IONPs made it possible to incorporate a variety of commonly used antibiotics such as the $\beta$-lactam amoxicillin, penicillin, and ampicillin, the aminoglycoside streptomycin, and the glycopeptide vancomycin (Chifiriuc et al., 2013; Grumezescu et al., 2014; Hussein-Al-Ali et al., 2014; El Zowalaty et al., 2015; Wang et al., 2017), providing evidence that biocompatible magnetic NPs might enable site-specific antibiotic delivery. Vancomycin-carrying, folic acid-tagged chitosan NPs were successfully used to deliver vancomycin to bacterial cells (Chakraborty et al., 2010, 2012), and vancomycin-modified mesoporous silica NPs were used for selective recognition and killing of Gram-positive bacteria over macrophage-like cells (Qi et al., 2013). An alternative use of IONPs functionalized with vancomycin - an antibiotic that binds to bacterial cell walls - was to apply them as ligands for the affinity capture of a wide range of bacteria from biological samples, including Gram-positive bacteria such as $S$. aureus and Gram-negative 
bacteria such as Escherichia coli (Gu et al., 2003; Lin et al., 2005; Kell et al., 2008). Because of the magnetic properties of vancomycin-functionalized IONPs, vancomycin-captured bacteria can be magnetically separated and concentrated from large volumes into much smaller volumes, allowing bacterial analysis and detection based on, for example, genomic DNA (Kell et al., 2008; Zhu et al., 2015).

In this work, we employed IONPs as carriers of the lipoglycopeptide antibiotic teicoplanin, which has been used in clinical practice since 1988 in Europe and 1998 in Japan. Teicoplanin is considered a drug of "last resort" for treating severe infections by multiresistant Gram-positive pathogens, including the methicillin-resistant S. aureus (MRSA) and the anaerobe Clostridioides difficile (Marcone et al., 2018). Teicoplanin is a complex molecule with a peptide core of seven aromatic amino acids tailored with sugar residues, chlorine atoms, methyl groups, and a lipid chain. It forms five specific hydrogen bonds with the D-alanyl-D-alanine terminus of the peptidoglycan precursors of the bacterial cell wall, blocking its synthesis and consequently causing cell lysis (Binda et al., 2014). The antibacterial spectrum of teicoplanin activity against Grampositive bacteria is similar to that of vancomycin, but teicoplanin shows an increased potency, particularly against some resistant clinical isolates belonging to Staphylococcus, Streptococcus, and Enterococcus genera (Van Bambeke, 2006). In addition, teicoplanin is active on vancomycin-resistant enterococci with VanB-phenotype (Van Bambeke, 2006; Binda et al., 2014). The superior antimicrobial potency of the lipoglycopeptide teicoplanin in comparison to the glycopeptide vancomycin is due to the in vivo membrane anchoring of the hydrophobic tail of teicoplanin, which strengthens the bond to membranelocalized peptidoglycan precursors and promotes synergic backto-back dimerization of antibiotic molecules (Allen and Nicas, 2003; Treviño et al., 2014). In addition, lipidation seems to represent the key functional difference between vancomycin and teicoplanin, which is related to their differing abilities of inducing glycopeptide antibiotic resistance response in enterococci and actinomycetes (Dong et al., 2002; Binda et al., 2018). To the best of our knowledge, this is the first study exploring the feasibility of conjugating teicoplanin to IONPs and testing the potential of nanoconjugated teicoplanin as a promising tool for treating bacterial infections caused by resistant bacteria.

\section{MATERIALS AND METHODS}

\section{Materials}

All chemical reagents, including acetonitrile $\left(\mathrm{CH}_{3} \mathrm{CN}\right)$, ammonium formate $\left(\mathrm{HCOONH}_{4}\right)$, ammonium hydroxide $\left(\mathrm{NH}_{4} \mathrm{OH}\right)$, APTES, boric acid $\left(\mathrm{H}_{3} \mathrm{BO}_{3}\right)$, crystal violet $\left(\mathrm{C}_{25} \mathrm{~N}_{3} \mathrm{H}_{30} \mathrm{Cl}\right), \quad 2^{\prime}, 7^{\prime}$-dichlorodihydrofluorescein (DCFHDA), $\quad N$-(3-dimethylaminopropyl)- $N^{\prime}$-ethylcarbodiimide hydrochloride (EDC), ethanol $\left(\mathrm{C}_{2} \mathrm{H}_{6} \mathrm{O}\right)$, ferric nitrate $\left[\mathrm{Fe}\left(\mathrm{NO}_{3}\right)_{3} \times 9 \mathrm{H}_{2} \mathrm{O}\right]$, formaldehyde $\left(\mathrm{CH}_{2} \mathrm{O}\right)$, glutaraldehyde $\left(\mathrm{C}_{5} \mathrm{H}_{8} \mathrm{O}_{2}\right)$, iron dichloride $\left(\mathrm{FeCl}_{2} \times 4 \mathrm{H}_{2} \mathrm{O}\right)$, iron trichloride $\left(\mathrm{FeCl}_{3} \times 6 \mathrm{H}_{2} \mathrm{O}\right), \quad N$-hydroxysuccinimide (NHS), nitric acid $\left(\mathrm{HNO}_{3}\right)$, osmium tetroxide $\left(\mathrm{OsO}_{4}\right)$, phosphate-buffered saline (PBS), sodium cacodylate $\left(\mathrm{C}_{2} \mathrm{H}_{7} \mathrm{AsO}_{2}\right)$, sodium chloride $(\mathrm{NaCl})$, sodium hydroxide $(\mathrm{NaOH})$, sodium 2- $(\mathrm{N}-$ morpholino)ethanesulfonic acid hemisodium salt (MES), and teicoplanin, were purchased from Sigma-Aldrich, Milan, Italy. The LIVE/DEAD BacLight fluorescence assay kit was purchased by Thermo Fisher Scientific, Monza, Italy. Epon-Araldite 812 was purchased from Electron Microscopy Sciences, Hatfield, PA, United States. All the chemical reagents were used without additional purification.

\section{Microbial Strains and Culture Conditions}

Escherichia coli ATCC 35218, Bacillus subtilis ATCC 6633, S. aureus ATCC 6538P (methicillin susceptible S. aureus, MSSA), S. aureus ATCC 43300 (MRSA), Enterococcus faecalis ATCC 29212, and E. faecalis ATCC 51299 (VanB phenotype) were obtained from the American Type Culture Collection (ATCC). E. faecalis 9160188401-EF-34 (VanA phenotype) is a clinical isolate, which was kindly provided by Laboratorio Microbiologia Clinica - Ospedale di Circolo, Varese, Italy. E. coli and B. subtilis were propagated overnight in Luria Bertani medium (LB, 2\% tryptone, $2 \%$ yeast extract, and $1 \% \mathrm{NaCl}$ ), and the $S$. aureus and E. faecalis strains in Müller Hinton broth 2 (MHB2, 0.3\% beef infusion solids, $1.75 \%$ casein hydrolysate, and $0.15 \%$ starch) with continuous shaking at $200 \mathrm{rpm}$ and $37^{\circ} \mathrm{C}$. For exponential growth, overnight cultures were transferred to fresh medium: inocula were prepared to start the cultures with an optical density at $600 \mathrm{~nm}\left(\mathrm{OD}_{600 \mathrm{~nm}}\right)$ of 0.1 in the final medium. For longterm preservation, bacterial cultures were stored at $-20^{\circ} \mathrm{C}$ in $20 \%$ glycerol. Media were acquired from Sigma-Aldrich, Milan, Italy, unless otherwise stated.

\section{Synthesis of the IONPs}

Iron oxide $\left(\mathrm{Fe}_{2} \mathrm{O}_{3}\right)$ NPs were synthesized using the coprecipitation method reported by Balzaretti et al. (2017). Briefly, under vigorous stirring for $30 \mathrm{~min}, 8.89 \mathrm{~g}$ of $\mathrm{FeCl}_{3} \times 6 \mathrm{H}_{2} \mathrm{O}$ and $3.28 \mathrm{~g} \mathrm{FeCl}_{2} \times 4 \mathrm{H}_{2} \mathrm{O}$ were mixed in $380 \mathrm{~mL}$ of water, while slowly adding $1.5 \mathrm{~mL}$ of $\mathrm{HCl}(37 \%)$ dropwise into the solution to completely dissolve the salts. Following this step, $25 \mathrm{~mL}$ of $\mathrm{NH}_{4} \mathrm{OH}$ (25\%) was added. Particles were washed several times with Milli-Q water and $40 \mathrm{~mL}$ of $2 \mathrm{M} \mathrm{HNO}_{3}$ was added and heated at $90^{\circ} \mathrm{C}$ for $5 \mathrm{~min}$. Then, particles were separated by a magnet from the reaction mixture; subsequently, $60 \mathrm{~mL}$ of $0.34 \mathrm{M}$ solution of $\mathrm{Fe}\left(\mathrm{NO}_{3}\right)_{3} \times 9 \mathrm{H}_{2} \mathrm{O}$ was added. The suspension was heated at $90^{\circ} \mathrm{C}$ for $30 \mathrm{~min}$. The supernatant was removed and IONPs were collected by a magnet, suspended in Milli-Q water, and left in dialysis overnight. IONPs were stored at $4^{\circ} \mathrm{C}$.

\section{Functionalization With APTES}

To prepare functionalized IONPs, a standard protocol (Balzaretti et al., 2017) was followed: a $1.5 \mathrm{M}$ solution of APTES in ethanol was added to $150 \mathrm{mg}$ of IONPs and stirred for $1 \mathrm{~h}$ at room temperature. Then, the temperature was increased to $90^{\circ} \mathrm{C}$ and the solution was stirred for an additional hour. The amino-modified IONPs (NP-APTES) were collected by a magnet, washed several times, and suspended in Milli-Q water. 


\section{Teicoplanin Conjugation to NP-APTES}

To prepare teicoplanin-conjugated NPs (NP-TEICO), a solution containing teicoplanin $(500 \mu \mathrm{g}), 13 \mathrm{mM} \mathrm{EDC}$, and $26 \mathrm{mM}$ NHS was prepared and added to the NP-APTES $(4 \mathrm{mg} / \mathrm{mL})$ dispersed in $30 \mathrm{mM}$ MES buffer at $\mathrm{pH} 6.0$ in a final volume of $1 \mathrm{~mL}$. The reaction was mixed for $6 \mathrm{~h}$ at room temperature. NP-TEICO were washed twice and resuspended in fresh $30 \mathrm{mM}$ MES buffer at pH 6.0.

\section{Characterization of NPs}

The shape, size, and size distribution of IONPs, NP-APTES, and NP-TEICO were investigated by transmission electron microscopy (TEM) using a JEOL 1010 electron microscope (Tokyo, Japan). Samples for TEM were dispersed in Milli-Q water on carbon-coated copper grids and dried at room temperature. The hydrodynamic diameter size and polydispersity index (PDI) of IONPs, NP-APTES, and NP-TEICO were measured in 0.9\% $\mathrm{NaCl}$. Zeta potential was measured on samples diluted in $1 \mathrm{mM} \mathrm{KCl}$ at $25^{\circ} \mathrm{C}$. Measurements were performed at $25^{\circ} \mathrm{C}$ using a 90 Plus Particle Size Analyzer (Brookhaven Instruments Corporation, NY, United States).

\section{HPLC Analysis}

Teicoplanin was measured by HPLC according to the method previously reported in Taurino et al. (2011). HPLC analyses were performed on a $5-\mu \mathrm{m}$ particle size Symmetry C18 (VWR International LCC, Radnor, PA, United States) column $(4.6 \mathrm{~mm} \times 250 \mathrm{~mm})$. The column was eluted at a $1 \mathrm{~mL} / \mathrm{min}$ flow rate with a 30 -min linear gradient from 15 to $65 \%$ of Phase B, followed by 10 min with $100 \%$ Phase B. For Phase A we used a $32 \mathrm{mM} \mathrm{HCOONH}$, pH 7.0: $\mathrm{CH}_{3} \mathrm{CN}$ 90:10 (v/v) mixture, and for Phase B a $32 \mathrm{mM} \mathrm{HCOONH} 4, \mathrm{pH}$ 7.0: $\mathrm{CH}_{3} \mathrm{CN}$ 30:70 (v/v) mixture. Chromatography was performed with a model 1100 HPLC system (Elite Lachrom Hitachi LLC, VWR, Milan, Italy) and UV detection was at $236 \mathrm{~nm}$.

\section{Agar Diffusion Test}

Antimicrobial activities of IONPs, NP-APTES, and NP-TEICO were tested against E. coli ATCC 35218, B. subtilis ATCC 6633, and S. aureus ATCC $6538 \mathrm{P}$ by employing an agar diffusion assay (Finn, 1959). Briefly, bacterial cultures were grown in MHB2 until an $\mathrm{OD}_{600} \mathrm{~nm}$ of 0.4 was reached and then used to prepare agar plates containing Müller-Hinton Agar (MHA). $10 \mu \mathrm{L}$ of IONPs, NP-APTES, NP-TEICO $(4 \mathrm{mg} / \mathrm{mL}$ loaded with $500 \mu \mathrm{g} / \mathrm{mL}$ of teicoplanin in the case of NP-TEICO), and of teicoplanin $(500 \mu \mathrm{g} / \mathrm{mL})$ in $30 \mathrm{mM}$ MES buffer, $\mathrm{pH}$ 6.0, were loaded manually onto the inoculated plates. The plates were incubated at $37^{\circ} \mathrm{C}$ for $24 \mathrm{~h}$. The diameters of the zones of bacterial growth inhibition surrounding the droplets were measured.

\section{Determination of Minimum Inhibitory Concentration and Minimum Bactericidal Concentration}

Minimum inhibitory concentrations (MICs) of non-conjugated and nanoconjugated teicoplanin were determined toward B. subtilis, S. aureus, and E. faecalis strains by applying the broth dilution method using MHB2, as recommended by the Clinical and Laboratory Standards Institute guidelines (CLSI, 2018). About $5 \times 10^{5}$ exponentially growing bacterial cells were inoculated into MHB2 containing increasing concentrations of teicoplanin and NP-TEICO in $30 \mathrm{mM}$ MES buffer, $\mathrm{pH}$ 6.0, and shaken for $16-20 \mathrm{~h}$ at $37^{\circ} \mathrm{C}$. NP-TEICO concentrations to be added were calculated considering the amount of teicoplanin loaded onto IONPs (nanoconjugated teicoplanin) under the reaction conditions described above. MICs were the minimal concentrations of nanoconjugated and non-conjugated teicoplanin at which no turbidity could be detected.

To evaluate the minimum bactericidal concentrations (MBCs), $100 \mu \mathrm{L}$ of bacterial cultures used for the MIC test were plated onto MHA and incubated at $37^{\circ} \mathrm{C}$ for $24 \mathrm{~h}$. MBCs were the minimal concentrations of nanoconjugated and non-conjugated teicoplanin at which no growth could be detected. The tolerance level of each tested bacterial strain toward nanoconjugated and non-conjugated teicoplanin was determined according to May et al. (1998) using the following formula: Tolerance $=$ MBC/MIC.

\section{Growth Kinetic Analysis}

Growth kinetics of B. subtilis ATCC 6633, S. aureus ATCC 6538P, and $E$. coli ATCC 35218 populations were followed by measuring $\mathrm{OD}_{600 \mathrm{~nm}}$ using an UV-Vis V-560 Spectrophotometer (JASCO, MD, United States) at regular time intervals. Preinocula were prepared from overnight cultures in $\mathrm{LB}$ or $\mathrm{MHB} 2$ at $37^{\circ} \mathrm{C}$ and at $200 \mathrm{rpm}$. Experiments were conducted in $50-\mathrm{mL}$ tubes containing a final volume of $10 \mathrm{~mL}$ of LB or MHB2 added after $1 \mathrm{~h}$ of growth from inocula with equivalent volumes of IONPs, NP-APTES, and NP-TEICO preparations $(4 \mathrm{mg} / \mathrm{mL})$ previously resuspended in $30 \mathrm{mM}$ MES buffer, $\mathrm{pH} 6.0$, or with the teicoplanin control solution $(500 \mu \mathrm{g} / \mathrm{mL})$.

\section{Viability Assay}

Viable counts (expressed as colony-forming units per $\mathrm{mL}$, $\mathrm{CFU} / \mathrm{mL}$ ) were estimated by employing the plate count technique. For CFU measurement, a standard volume $(10 \mu \mathrm{L})$ of undiluted or serially diluted samples collected from stationary phase cultures on treatment with teicoplanin, IONPs, NP-APTES, and NP-TEICO, as reported above, were plated on nutrient agar. Plates were incubated for $24 \mathrm{~h}$ at $37^{\circ} \mathrm{C}$ to evaluate the viable cells.

\section{Fluorescence Microscopy Analysis}

To investigate the effect of IONPs, NP-APTES, and NP-TEICO on bacterial cells, the LIVE/DEAD BacLight fluorescence assay was used (L7007, Molecular probes, Thermo Fisher Scientific). Following the manufacturer's protocol, bacteria were cultivated overnight at $37^{\circ} \mathrm{C}$ and agitated at $200 \mathrm{rpm}$, appropriately diluted, and treated for $5 \mathrm{~h}$ with $4 \mathrm{mg} / \mathrm{mL}$ of IONPs, NP-APTES, and NPTEICO and teicoplanin $(500 \mu \mathrm{g} / \mathrm{mL})$. From these cultures, $10 \mathrm{~mL}$ of each bacterial solution was centrifuged at $7000 \mathrm{rpm}$ for $15 \mathrm{~min}$. The supernatants were discarded and the pellets were suspended in saline solution $(0.9 \%)$. The samples were incubated at room temperature for $1 \mathrm{~h}$ (mixing every $15 \mathrm{~min}$ ) and then washed twice with saline solution. Finally, the pellets were resuspended in an equal volume of saline solution $(0.9 \%)$. Then, $3 \mu \mathrm{L}$ of dye mixture was added to each $1 \mathrm{~mL}$ of the prepared bacterial 
samples and incubated in the dark for 15 min after properly mixing the bacterial suspensions. Fluorescence images were taken by trapping $5 \mu \mathrm{L}$ of stained bacterial samples between a slide and a cover slip. For imaging the samples, an optical microscope with appropriate filters was employed (Axiophot; Carl Zeiss, Milan, Italy). Image (Schneider et al., 2012) was used to quantify total fluorescence intensity of the bacteria. Intensities were expressed as percentage (\%) relative to the saturation fluorescence within the field; red and green fluorescence stains corresponded to live or dead bacteria, respectively (Borcherding et al., 2014; Arakha et al., 2015a,b).

\section{Transmission Electron Microscopy Analysis}

The interaction pattern of NPs with bacteria was also studied by TEM. After $5 \mathrm{~h}$ of exposure to $4 \mathrm{mg} / \mathrm{mL}$ IONPs, NP-APTES, NP-TEICO, or teicoplanin $(500 \mu \mathrm{g} / \mathrm{mL})$, pellets were washed with PBS and fixed in Karnovsky solution (4\% formaldehyde, $2 \%$ glutaraldehyde, $0.1 \mathrm{M}$ sodium cacodylate, $\mathrm{pH}$ 7.2) overnight at $4^{\circ} \mathrm{C}$. The samples were washed three times with $0.1 \mathrm{M}$ sodium cacodylate for $10 \mathrm{~min}$ and postfixed in the dark for $1 \mathrm{~h}$ with $1 \%$ osmium tetroxide in $0.1 \mathrm{M}$ sodium cacodylate buffer, $\mathrm{pH}$ 7.2, at room temperature. After dehydration with a series of ethyl alcohol, the samples were embedded in an EponAraldite 812 1:1 mixture. Thin sections (90 nm), obtained with a Pabisch Top-Ultra ultramicrotome (Emme 3 S.r.l., Milan, Italy), were observed with a Morgagni electron microscope (Philips, Eindhoven, Netherlands) operated at $80 \mathrm{keV}$.

\section{Biofilm Assay}

S. aureus ATCC 6538P cultures, grown overnight in LB, were diluted in fresh medium to reach a cell density of $10^{7}$ $\mathrm{CFU} / \mathrm{mL}$ and dispensed in 24-well plates, adding increasing concentrations of nanoconjugated or non-conjugated teicoplanin $(2.5,5$, and $10 \mu \mathrm{g} / \mathrm{mL})$ and of naked IONPs or NP-APTES $(20,40$, and $80 \mu \mathrm{g} / \mathrm{mL})$. The amounts of NPs to be added took into account the teicoplanin loaded on NPs under the reaction conditions described above. Following incubation at $37^{\circ} \mathrm{C}$ for $24 \mathrm{~h}$, the adherent biomass was quantified by crystal violet (CV) staining. Biofilms were stained with CV $0.1 \%$ for $20 \mathrm{~min}$, washed twice with PBS, and air dried overnight at room temperature; the CV was then dissolved in $33 \%$ acetic acid for $10 \mathrm{~min}$. The amount of solubilized dye was spectrophotometrically measured at $595 \mathrm{~nm}$ (Infinite 200 PRO; TECAN, Männedorf, Switzerland). To assess the effect of teicoplanin and of NP preparations on the cell viability of planktonic and adherent cell subpopulations, cells from the planktonic phase were collected and adherent cells were recovered by scraping the wells and then suspended in $1 \mathrm{~mL}$ of phosphate buffer. Cultures were diluted and CFU were estimated by plate counting in MHA plates. Viable counts of planktonic cells were expressed as CFU/mL and adherent cells as CFU per well (CFU/well).

To test the effect of teicoplanin and NP preparations on biofilm dispersal, biofilms were prepared as indicated previously and incubated at $37^{\circ} \mathrm{C}$ for $48 \mathrm{~h}$ before adding nanoconjugated or non-conjugated teicoplanin $(5,25$, and $50 \mu \mathrm{g} / \mathrm{mL})$ and naked
IONPs or NP-APTES $(40,200$, and $400 \mu \mathrm{g} / \mathrm{mL})$. Following 24-h incubation at $37^{\circ} \mathrm{C}$, biofilm biomass was evaluated by $\mathrm{CV}$ staining and the cell viability of adherent and planktonic cells was estimated by applying the viable count technique, as previously described.

\section{Cell Cultures}

Two different cell lines were used to evaluate NP-TEICO in vitro cytotoxicity: a tumor model SKOV-3 cell line from ovarian adenocarcinoma and a non-tumor cell line, hASCs (human adipose-derived stem cells). SKOV-3 cells were cultured as reported in the literature (Cappellini et al., 2015). hASCs were isolated and cultured as previously reported (Palombella et al., 2017).

\section{Cytotoxicity Test}

Cell cytotoxicity was determined by measuring ATP content using the RealTime-Glo ${ }^{\mathrm{TM}}$ MT Cell Viability Assay (Promega, Milan, Italy) according to the manufacturer's instructions. Briefly, 500 cells were plated in 96-well plates in $200 \mu \mathrm{L}$ of cell medium (RPMI for SKOV-3 and DMEM/DMEM F12 1:1 for hASC). After $24 \mathrm{~h}$, the cells were exposed to increasing concentrations of nanoconjugated or non-conjugated teicoplanin or to the corresponding concentrations of NPs (considering the teicoplanin loaded per mg of NPs) and then a solution $2 \times$ the substrate and NanoLuc ${ }^{\circledR}$ Enzyme were added. The cells were incubated at $37^{\circ} \mathrm{C}$ and in $5 \% \mathrm{CO}_{2}$-humidified atmosphere, and luminescence was read every $24 \mathrm{~h}$ using the Infinite F200 plate reader (Tecan Group, Männedorf, Switzerland).

\section{Statistics}

All experiments were repeated at least three times on separate dates. Mean and standard deviation (SD) calculations were performed using Microsoft Excel 2003 (Microsoft Corporation, Redmond, WA, United States). Data were analyzed by means of one-way analysis of variance (Origin_7.0 SR0; Origin lab Corporation, Northampton, MA, United States). Significant effects of treatments were estimated $(p<0.05, p<0.01$, and $p<0.0001)$.

\section{RESULTS}

\section{Characterization of Synthetized NPs}

Numerous methods for synthesizing IONPs have been reported in the literature (Wu et al., 2015). In this study, we used the coprecipitation method previously optimized by Balzaretti et al. (2017), by which IONPs with good stability and size distribution and no tendency to aggregation could be produced. We confirmed that the NPs obtained had a spherical shape and an average diameter of $10.5 \pm 4 \mathrm{~nm}$, as shown by TEM micrograph (Figures 1A,D). The functionalization protocol, used to introduce amino groups on the IONPs (Figure 2), led to an insignificant increase in the diameter of NP-APTES, which was $10.6 \pm 3.6 \mathrm{~nm}$ (Figures 1B,E). Teicoplanin was conjugated by following a slightly modified protocol, which was previously used for enzyme conjugation (Armenia et al., 2017): carboxylic groups 

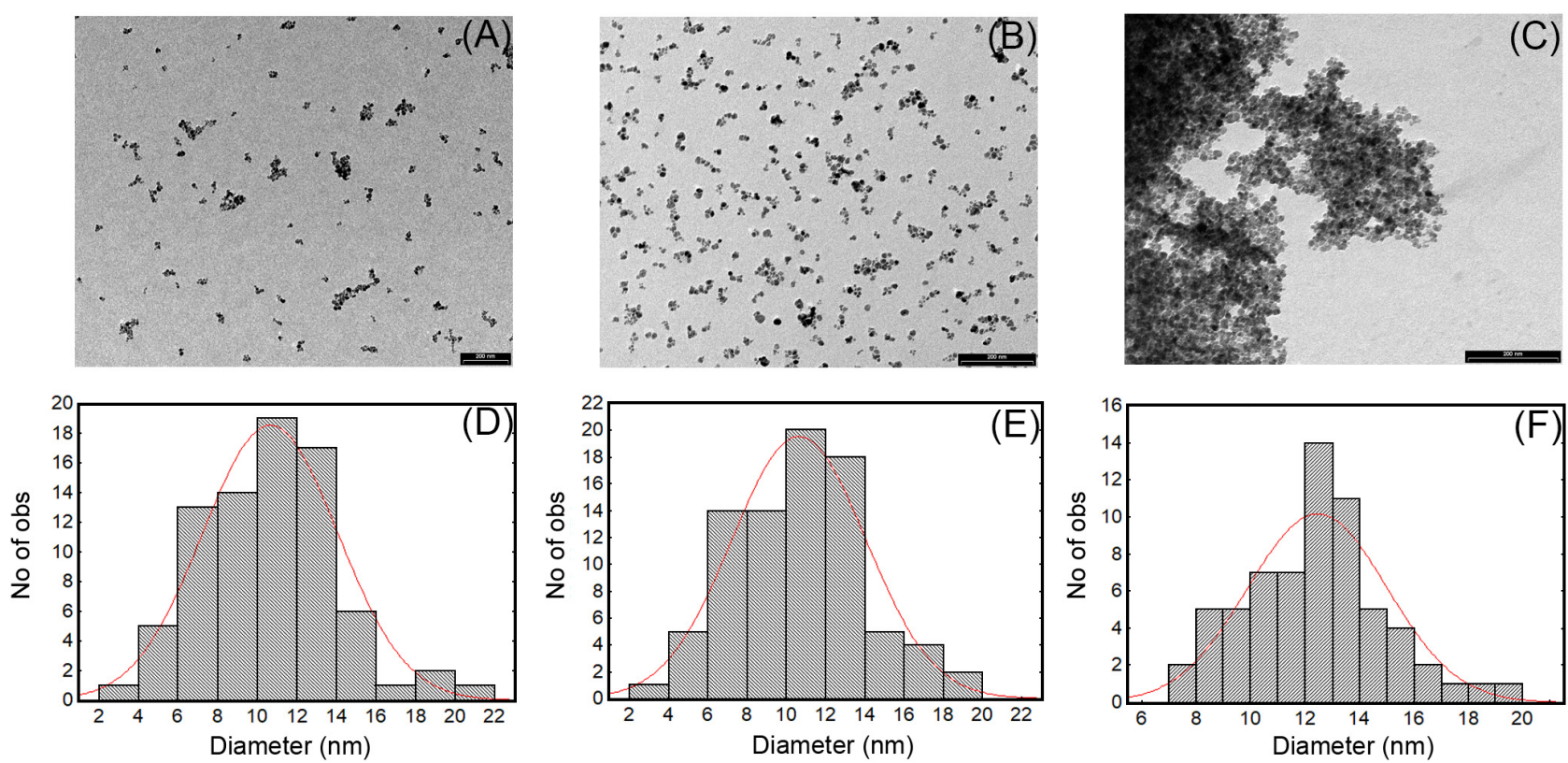

FIGURE 1 | TEM images and size distribution of IONPS (A,D), NP-APTES (B,E), and NP-TEICO (C,F).

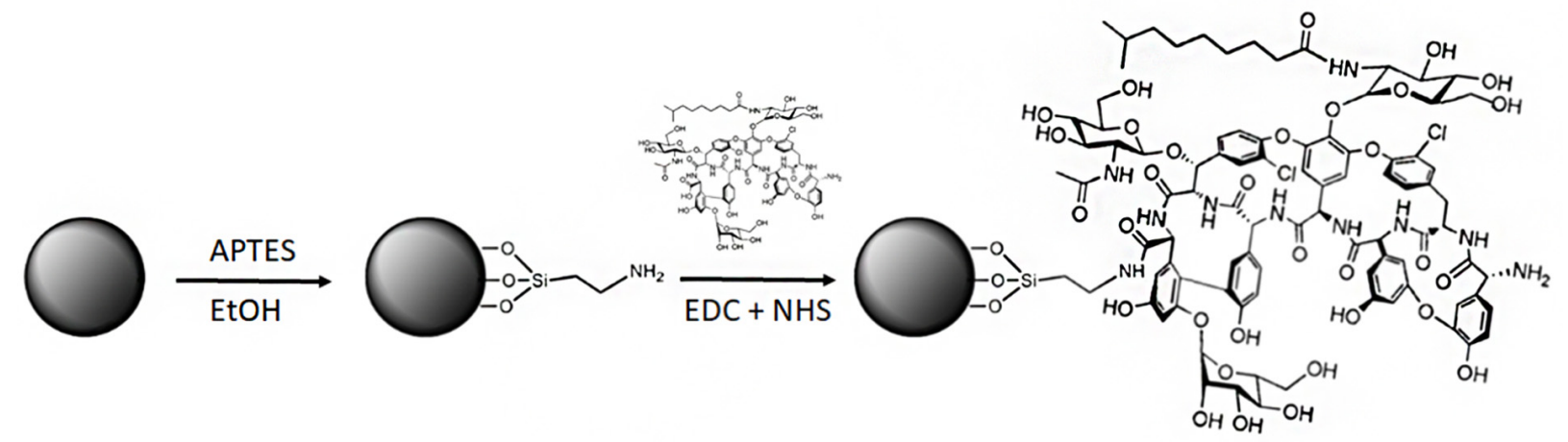

FIGURE 2 | Synthetic route for teicoplanin conjugation to IONPS (not in scale). The first step is functionalization of the IONPs with APTES, followed by the conjugation of teicoplanin by covalent bonding of the terminal carboxylic groups of the antibiotic molecules with the amino groups of NP-APTES via EDC/NHS cross-linking.

of teicoplanin molecules reacted with the amino groups on the surface of NP-APTES after EDC/NHS antibiotic activation (see below, Figure 2). Teicoplanin conjugation led to a more irregular shape of the particles and a slight tendency to aggregation. It is known that correctly conformed teicoplanin molecules tend to dimerize back-to-back in aqueous solutions and that dimerization plays an important role in their biological activity (Treviño et al., 2014). However, this phenomenon was not strong as no NP precipitation occurred. NP-TEICO had an average diameter of $13.6 \mathrm{~nm}$ (Figures 1C,F).

Transmission electron microscopy observations were complemented by measuring dynamic light scattering (DLS) of the hydrodynamic size of IONPs (Table 1); their diameter was estimated to be $14.2 \pm 0.5 \mathrm{~nm}$ with an average size distribution (PDI) of 0.127 , indicating a slight polydispersity typical for the coprecipitation synthesis (Wu et al., 2015). For NP-APTES, an increase in the hydrodynamic diameter $(26.8 \pm 0.2 \mathrm{~nm})$ due to the presence of the APTES shell around the NP core was registered. The hydrodynamic diameter of NP-TEICO was much larger (568.2 $\pm 0.6 \mathrm{~nm}$ ) (Table 1), probably due to aggregate formation in the medium used for DLS analysis and to the effect of the glycopeptide side chains and their tendency to dimerize, which might slow down particle diffusion and increase their apparent size (Szpak et al., 2013; Table 1). The difference in NP sizes measured by DLS versus TEM is generally attributed to the formation of extra hydrate layers in aqueous solutions (De Palma et al., 2007; Gonçalves et al., 2017). In addition, antibiotic shells conjugated to NPs are usually not sufficiently electron dense to be visible under the electron microscope. The measurement of zeta potential (Table 1) showed that the superficial charge of 
TABLE 1 | Physical parameters of synthesized IONPs, NP-APTES, and NP-TEICO.

\begin{tabular}{|c|c|c|c|c|c|c|}
\hline & Baseline & Polydispersity & Diameter (nm) & Conductance $(\mu \mathrm{S})$ & Mobility & $\mathrm{Z}$ potential $(\mathrm{mV})$ \\
\hline IONPS & 9.9 & 0.127 & $14.2 \pm 0.5$ & 421 & 1.5 & $11.0 \pm 0.8$ \\
\hline NP-APTES & 9 & 0.18 & $26.8 \pm 0.2$ & 373 & 1.9 & $22.5 \pm 0.5$ \\
\hline NP-TEICO & 9 & 0.189 & $568.2 \pm 0.6$ & 400 & 1 & $12.8 \pm 0.6$ \\
\hline
\end{tabular}

NP-APTES was twofold higher than for IONPs, that is, $22.5 \pm 0.2$ versus $11 \pm 0.8 \mathrm{mV}$, due to the presence of the amino groups of APTES. A reduction in the surface charge was indeed observed after teicoplanin conjugation: NP-TEICO zeta potential was $12.8 \pm 0.6 \mathrm{mV}$, indicating that NP-APTES were successfully loaded with teicoplanin.

\section{Preparation of NP-TEICO}

Teicoplanin was conjugated to NP-APTES using standard EDC/NHS chemistry: EDC reacted with the carboxylic group of the antibiotic, forming an active $\mathrm{O}$-acylisourea intermediate that could be displaced by the nucleophilic attack of the amino groups present on the NP-APTES surface (Figure 2; Hermanson, 2013). Different reaction conditions (reaction medium, EDC/NHS ratio, teicoplanin concentration, time, and temperature of reaction) were explored to improve teicoplanin conjugation on NP-APTES. The quantity of teicoplanin bound to the surface of NP-APTES was estimated by subtracting the unreacted teicoplanin present in the supernatant from the added total antibiotic amount. Teicoplanin was quantified by reverse-phase HPLC as previously reported (Taurino et al., 2011). First trails in water, PBS, and MES buffer indicated that the latter, at $\mathrm{pH}$ 6.0, was the most preferable medium for the conjugation reaction (data not shown). As reported in Table 2, HPLC analyses confirmed that under the best experimental conditions tested so far, that is, $4 \mathrm{mg} / \mathrm{mL}$ of NPAPTES in $30 \mathrm{mM}$ MES buffer, pH 6.0, 13 mM EDC, $26 \mathrm{mM}$ NHS, $500 \mu \mathrm{g} / \mathrm{mL}$ of teicoplanin, the teicoplanin conjugation yield was

TABLE 2 | Reaction conditions tested for teicoplanin conjugation to NP-APTES via EDC/NHS chemistry in $30 \mathrm{mM}$ MES, pH 6.0.

\begin{tabular}{lccccc}
\hline $\begin{array}{l}\text { Teicoplanin } \\
(\boldsymbol{\mu} \mathbf{g} / \mathbf{m L})\end{array}$ & $\begin{array}{c}\text { EDC } \\
(\mathbf{m M})\end{array}$ & $\begin{array}{c}\text { NHS } \\
(\mathbf{m M})\end{array}$ & $\begin{array}{c}\text { Temperature } \\
\left({ }^{\circ} \mathbf{C}\right)\end{array}$ & $\begin{array}{c}\text { Time } \\
\mathbf{( h )}\end{array}$ & Yield (\%) \\
\hline 100 & 26 & 13 & 4 & 2 & $10 \pm 0.7$ \\
100 & 26 & 13 & 4 & 4 & $10 \pm 1.5$ \\
100 & 26 & 13 & 4 & 6 & $12 \pm 1.0$ \\
100 & 26 & 13 & 25 & 2 & $25 \pm 0.5$ \\
100 & 26 & 13 & 25 & 4 & $30 \pm 0.4$ \\
100 & 26 & 13 & 25 & 6 & $65 \pm 0.8$ \\
100 & 13 & 26 & 25 & 2 & $70 \pm 1.7$ \\
100 & 13 & 26 & 25 & 4 & $85 \pm 1.4$ \\
50 & 13 & 26 & 25 & 6 & $100 \pm 1.2$ \\
100 & 13 & 26 & 25 & 6 & $100 \pm 0.7$ \\
500 & 13 & 26 & 25 & 6 & $90 \pm 0.9$ \\
1000 & 13 & 26 & 25 & 6 & $50 \pm 0.5$ \\
\hline
\end{tabular}

NP-APTES were used at a concentration of $4 \mathrm{mg} / \mathrm{mL}$. Conjugation yield was calculated by estimating the amount of residual teicoplanin in the reaction medium by HPLC. approximately 90\%. Under these conditions, more than $100 \mu \mathrm{g}$ of teicoplanin was loaded per mg of NP-APTES.

NP-TEICO prepared in this way remained chemically stable when stored at pHs ranging from 5.5 to 7.1 and temperatures from -20 to $25^{\circ} \mathrm{C}$. Under these conditions, release of teicoplanin from NP-TEICO was measured by HPLC analysis of incubation buffer; $100 \%$ of the antibiotic remained fully attached to NPs for 1 week and decreased by approximately $10 \%$ in 1 month (data not shown). Consistently, the antimicrobial activity of NPTEICO - measured by the antimicrobial susceptibility test versus S. aureus ATCC 6538P and B. subtilis ATCC 6633 (see below) was also maintained. After 3 weeks, NP-TEICO maintained from 70 to $90 \%$ of its initial antimicrobial activity. Under the same conditions, a water solution of teicoplanin $(500 \mu \mathrm{g} / \mathrm{mL})$ maintained $90 \%$ of its initial antimicrobial activity.

\section{Antimicrobial Activity of NP-TEICO}

Antibacterial activity of NP-TEICO was initially investigated by comparing the growth inhibitory effects of two commonly used representative species of Gram-positive bacteria, that is, $S$. aureus ATCC 6538P and B. subtilis ATCC 6633, and the Gram-negative E. coli ATCC 35218, using an agar diffusion assay. Figure 3 reveals that NP-TEICO inhibited the growth of $S$. aureus and

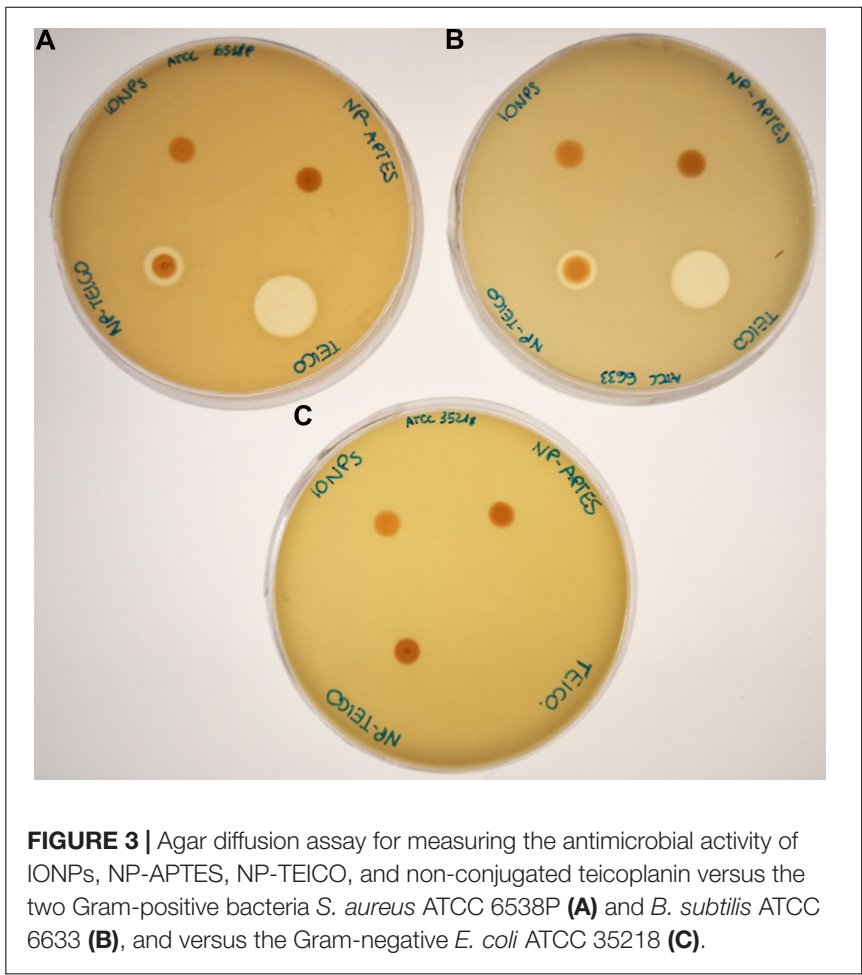


B. subtilis, whereas no inhibition halos were observed for E. coli, thus demonstrating that NP-TEICO maintained the typical activity and spectrum of action of teicoplanin. Sizes of inhibition halos for the nanoconjugated teicoplanin were not comparable with the ones determined by the non-conjugated teicoplanin, as expected, considering the probably slower diffusion rate of NP-loaded antibiotic in agar medium. Conversely, IONPs and NP-APTES did not show any inhibition halos toward either the Gram-positive or the Gram-negative bacteria. These data indicate that the antimicrobial activity measured by the agar diffusion assay was conferred to NP-TEICO by the conjugation of the antibiotic and that it was not an intrinsic feature of IONPs.

Table 3 reports the MICs of nanoconjugated and nonconjugated teicoplanin toward clinically relevant strains of S. aureus and E. faecalis. Although the potency of nanoconjugated teicoplanin was slightly reduced in comparison with the non-conjugated antibiotic, NP-TEICO maintained a valuable antibiotic activity against MRSA and on vancomycin-resistant E. faecalis with a VanB phenotype. MICs and MBCs, and consequently the tolerance levels of NP-TEICO toward B. subtilis, $S$. aureus, and E. faecalis, showed the same trend as those measured for non-conjugated teicoplanin. NP-TEICO and nonconjugated teicoplanin were inactive toward the Gram-negative E. coli and toward the vancomycin- and teicoplanin-resistant E. faecalis clinical isolate with a VanA phenotype (Van Bambeke, 2006; Binda et al., 2014).

\section{Effects of NPs on Bacterial Growth Kinetics and Cell Viability}

As the antimicrobial activity of IONPs and their derivatives is a matter of intensive debate (Auffan et al., 2008; Chatterjee et al., 2011; Borcherding et al., 2014; Arakha et al., 2015a; Ansari et al., 2017), we further investigated the effects of IONPs, NPAPTES, and NP-TEICO on bacterial cell viability, by adding our NP preparations at the log phase of the growth kinetics of S. aureus ATCC 6538P, B. subtilis ATCC 6633, and E. coli ATCC 35218 populations. Cultures with no added NP or to which only teicoplanin was added were used as negative and positive controls. Figure $\mathbf{4}$ indicates that the three bacterial species responded differently to NP interaction. S. aureus growth kinetics (Figure 4A) were dramatically affected by the addition of NP preparations and, as expected, by the treatment with teicoplanin. Albeit with a slightly different kinetics, cell density appeared equally reduced by two-thirds on $5 \mathrm{~h}$ of incubation. Indeed, NP-TEICO and non-conjugated teicoplanin drastically reduced the population growth of $B$. subtilis, whereas the effects of IONPs and NP-APTES were clearly less relevant (Figure 4B). Finally, teicoplanin was completely inactive toward the Gramnegative E. coli, whereas the addition of IONPs, NP-APTES, and NP-TEICO halved the population growth in a comparable mode (Figure 4C).

Significantly, CFU measurements at the end of the growth kinetics reported in Figure 5 clearly indicate that exposure of Gram-positive bacteria to teicoplanin and NP-TEICO cleared the bacteria population, confirming the comparable antibiotic activity of the nanoconjugated versus the non-conjugated antibiotic (Figure 5). As expected, teicoplanin and NP-TEICO were ineffective against $E$. coli cells, which conforms to the antimicrobial spectrum of the antibiotic. In addition, exposure to IONPs and NP-APTES was not bactericidal for any of the tested strains as the cells survived quite well, and in some cases (E. coli) even better than the untreated cultures. Thus, we can conclude that NP-TEICO retained an antibiotic activity that was comparable to that of the non-conjugated teicoplanin, whereas IONPs and NP-APTES showed a species-specific transient interaction with bacterial cells, which slowed down population growth but did not kill bacterial cells. This phenomenon merits further investigation.

\section{Interaction Patterns of NPs With Bacterial Cells}

To shed light on the interaction pattern at the IONPs-, NPAPTES- and NP-TEICO-bacteria interfaces, we investigated the effect of adding NP on bacterial cell integrity by using the

TABLE 3 | Comparison of MICs, MBCs, and tolerance levels between non-conjugated and nanoconjugated teicoplanin.

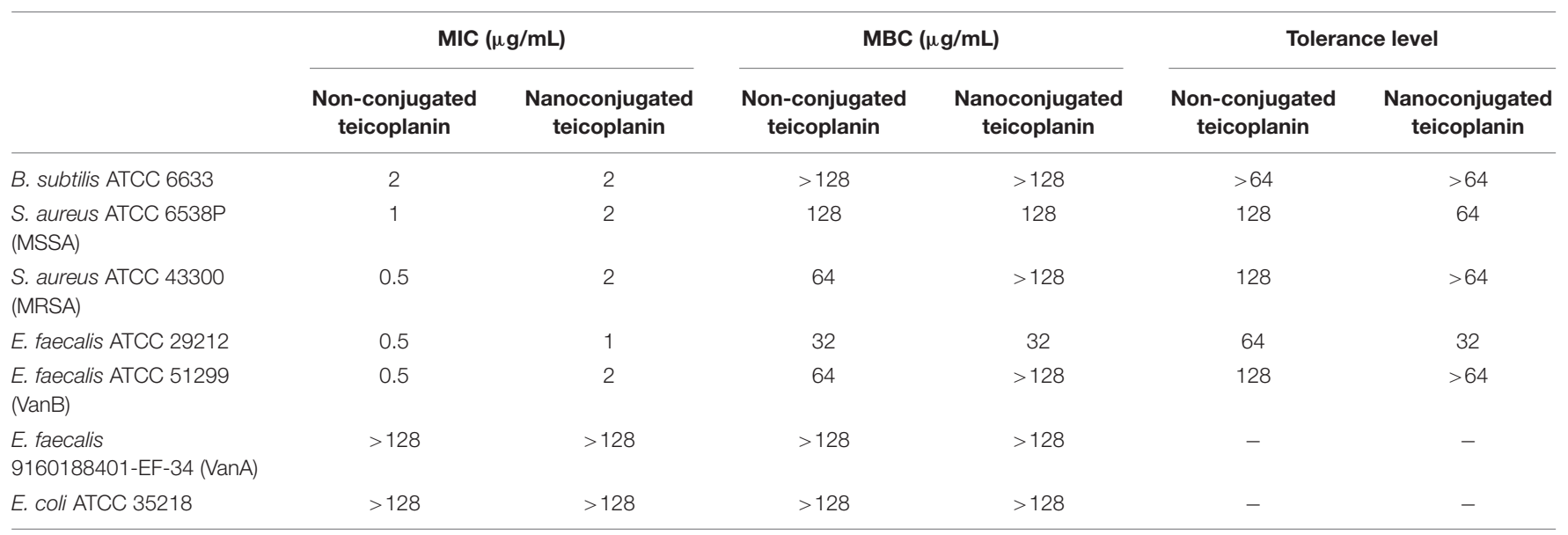

The values represent the average of the data from three independent experiments. 

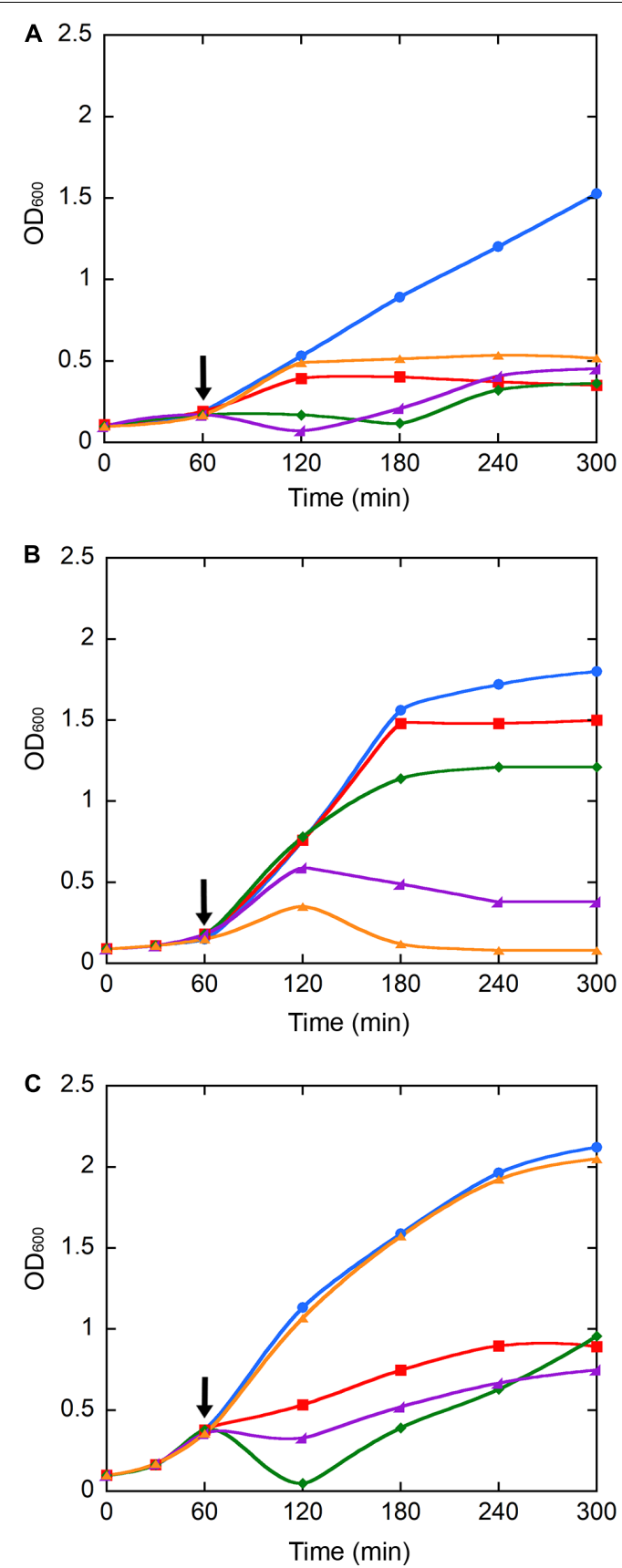

FIGURE 4 | Population growth kinetics of S. aureus ATCC 6538P (A), B. subtilis ATCC 6633 (B), and E. coli ATCC 35218 (C) exposed to teicoplanin (orange), IONPs (red), NP-APTES (green), and NP-TEICO (violet). Cultures without any addition (blue) were used as controls. Growth was recorded for $5 \mathrm{~h}$. Black arrows indicate the addition (after $1 \mathrm{~h}$ of growth) of NP preparations and of teicoplanin to the bacterial populations. Triplicate experiments were conducted for each condition: standard errors were lower than $5 \%$.

LIVE/DEAD BacLight fluorescence assay. According to the assay principle and as shown in Figure 6, viable cells having an intact cell membrane were stained green by the Syto 9 fluorescence dye, whereas non-viable cells with deformed cell membranes

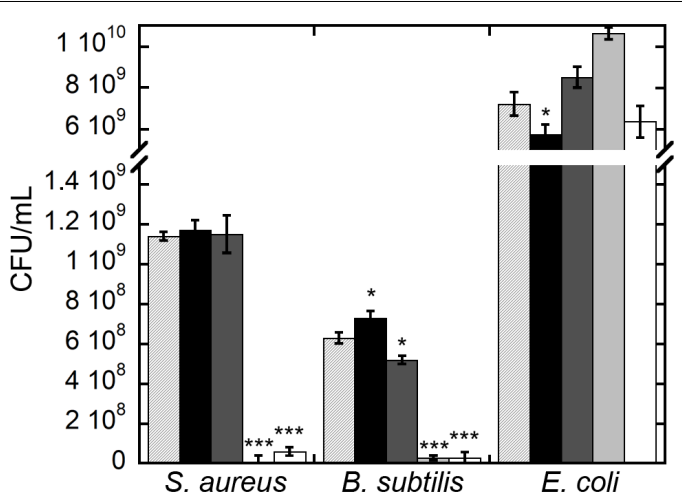

FIGURE 5 | Bacterial cell viability of $S$. aureus ATCC 6538 P, B. subtilis ATCC 6633, and E. coli ATCC 35218 measured as CFUs after 5-h growth (see Figure 4) in the presence of IONPs (black bar), NP-APTES (gray bar), NP-TEICO (light gray bar), and teicoplanin (white bar) compared to the untreated control populations (lined bar). Triplicate experiments were conducted for each condition, and the error bars represent the standard errors. One-way ANOVA analyses, ${ }^{*} p<0.05$ and ${ }^{* * *} p<0.0001$.

were stained red by propidium iodide fluorescence dye (Arakha et al., 2015a). As shown in Figures 6A-C, untreated cells of S. aureus ATCC 6538P, B. subtilis ATCC 6633, and E. coli ATCC 35218 exhibited green fluorescence, indicating the presence of $99 \%$ viable cells. Figures 6D-L show that both Grampositive and Gram-negative bacteria tended to aggregate on NPs when present. In the presence of IONPs and NP-APTES, the $S$. aureus population exhibited almost $90 \%$ of green viable cells (Figures 6D,G), whereas more than $50 \%$ cells turned to red fluorescence on exposure to NP-TEICO (Figure 6J). On the other hand, the B. subtilis population exposed to IONPs (Figures $6 \mathbf{E}, \mathbf{H}$ ) exhibited the presence of $75 \%$ green viable cells, whereas the $95 \%$ of B. subtilis cells treated with NP-TEICO were red (Figure 6K), indicating that nanoconjugated teicoplanin caused a severe loss of membrane integrity and cell viability. Control populations of S. aureus and B. subtilis treated with non-conjugated teicoplanin exhibited $98 \%$ of red non-viable cells (Figures $6 \mathbf{M}, \mathbf{N}$ ). In the presence of IONPs, NP-APTES, NP-TEICO, and teicoplanin, the fraction of red fluorescent $E$. coli cells was insignificant compared to untreated cells (Figures 6F,I,L,O). Once again, these observations confirm that the three bacterial species responded as expected to nanoconjugated and non-conjugated teicoplanin antibiotic action. They also suggest that naked IONPs and NP-APTES interacted with the different bacteria in a speciesspecific mode, likely depending on the diverse bacterial surface composition, as already suggested by other authors (Huang et al., 2010; Ebrahiminezhad et al., 2014; Arakha et al., 2015a; Dinali et al., 2017).

Transmission electron microscopy images (Figures 7A,D,G,J,M) indicated that the exposure of $S$. aureus ATCC 6538P cells to IONPs, NP-APTES, NP-TEICO, and teicoplanin significantly altered cell morphology in comparison to the untreated cells. IONPs, NP-APTES, and, to a significantly greater extent, NP-TEICO interacted with the cell wall of this Gram-positive species. In the presence of NP-APTES, 


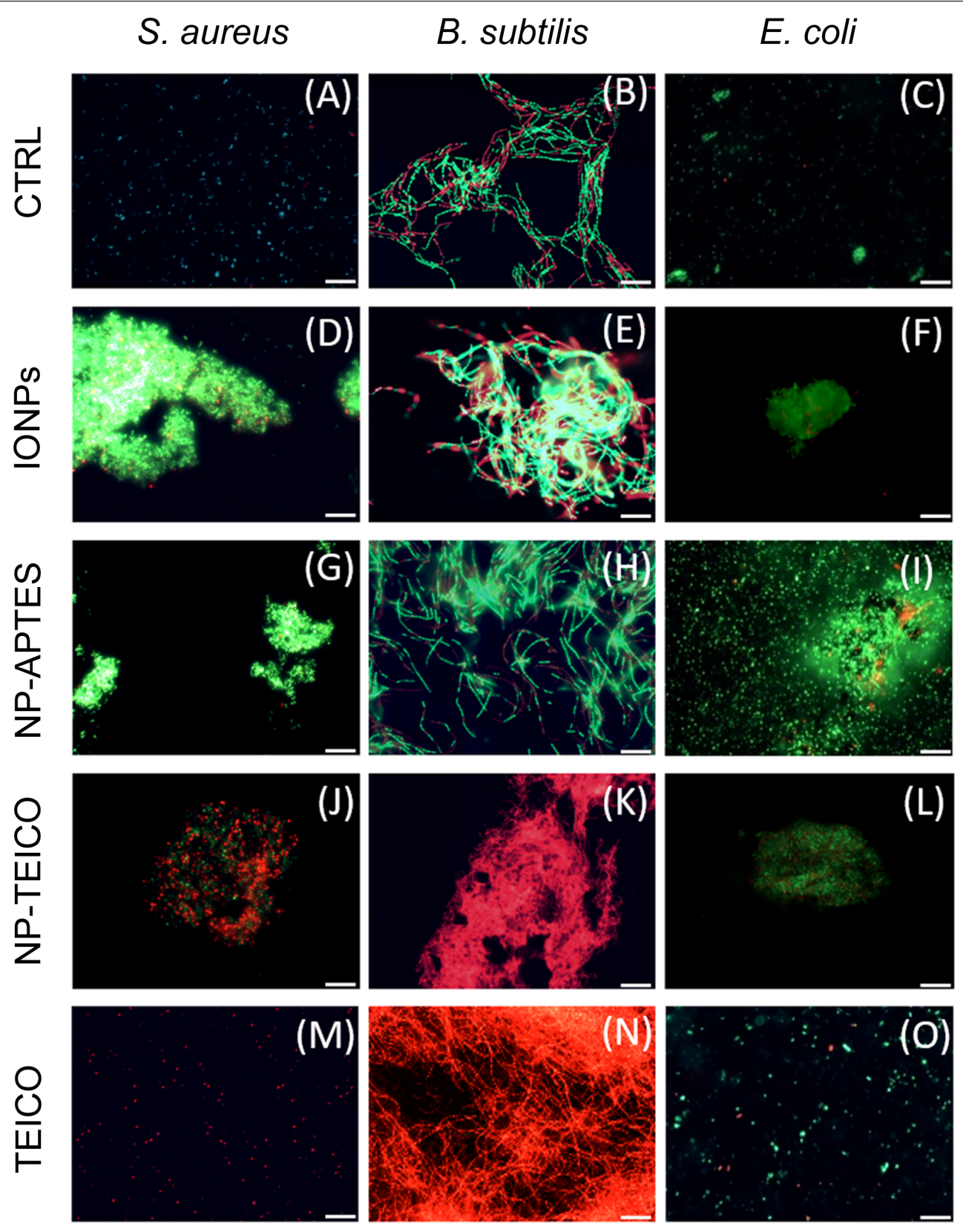

FIGURE 6 | Fluorescence microscopy images of live and dead cells of S. aureus ATCC 6538P [first column on the left: (A,D,G,J,M)], B. subtilis ATCC 6633 [middle column: (B,E,H,K,N)], and E. coli ATCC 35218 [column on the right: (C,F,I,L,O)] in the absence and presence of different NP preparations and of teicoplanin. (A-C) untreated cells; (D-F) cells treated with IONPS; (G-I) cells treated with NP-APTES; (J-L) cells treated with NP-TEICO; (M-O) cells treated with teicoplanin. Scale bar: $12 \mu \mathrm{m}$

NP-TEICO, and teicoplanin, an increasing percentage of cells without cell walls, so-called ghost cells, became detectable (Figures 8A,B). Lysed cells, too, which presented damage in cell walls with cytoplasmic content leaking out, were visible within NP-APTES- and NP-TEICO-treated cells (Figures 8A,C). Furthermore, in the presence of NP-APTES and NP-TEICO, intracellular spherical membrane-layered, mesosome-like structures could be detected inside the cells (Figures 8A,B). Mesosomes were previously described by other authors (Shimoda et al., 1995; Hartmann et al., 2010), as a consequence of cell membrane damage in $S$. aureus cells treated with antimicrobial peptides such as defensins and gramicidin $\mathrm{S}$.

Conversely, most of the B. subtilis ATCC 6633 cells (Figures 7B,E,H) exposed to IONPs and NP-APTES showed the same morphology as untreated cells, with undamaged structures, although a few dead or dying cells were detected, characterized by a rough surface and by an interrupted cell membrane. Indeed, 
S. aureus
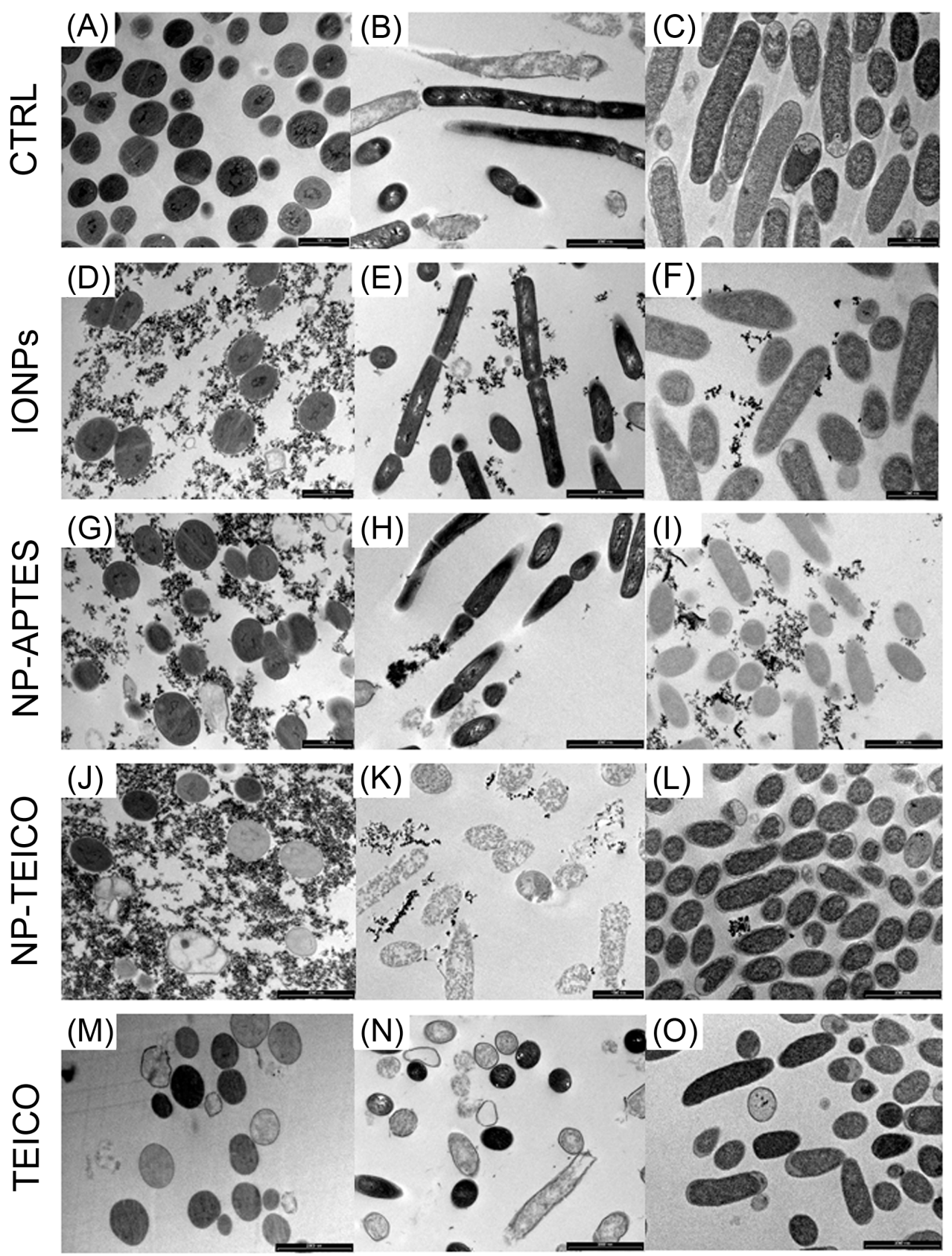

FIGURE 7 | TEM images of S. aureus ATCC 6538P [first column on the left: (A,D,G,J,M)], B. subtilis ATCC 6633 [middle column: (B,E,H,K,N)], and E. coli ATCC 35218 [column on the right: (C,F,I,L,O)] cells in the absence and presence of different NP preparations and of teicoplanin. (A-C) untreated cells; (D-F) cells treated with IONPs; (G-I) cells exposed to NP-APTES; (J-L) cells exposed to NP-TEICO; (M-O) cells treated with teicoplanin. Scale bars: $1 \mu \mathrm{m}$.

the effect of NP-TEICO and teicoplanin on cell integrity was dramatic (Figures $7 \mathbf{K}, \mathbf{N}$ ). Cells treated with NP-TEICO and teicoplanin lost their envelope integrity as a consequence of the antibiotic action (Figures 8D,E).

No specific alteration in cell morphology was observed in NP- or antibiotic-treated cells of E. coli in comparison to the untreated ones (Figures 7C,F,I,L,O). Interestingly, in this case,
IONPs and, to a much greater extent, NP-APTES tended to stick to the microorganism envelope, whereas the presence of NP-TEICO impeded this interaction. This observation seems to confirm the occurrence of an unspecific electrostatic interaction between positively charged NP-APTES and the negatively charged external cell membrane of this Gram-negative strain, which was previously suggested by other authors (Kell et al., 2008; 

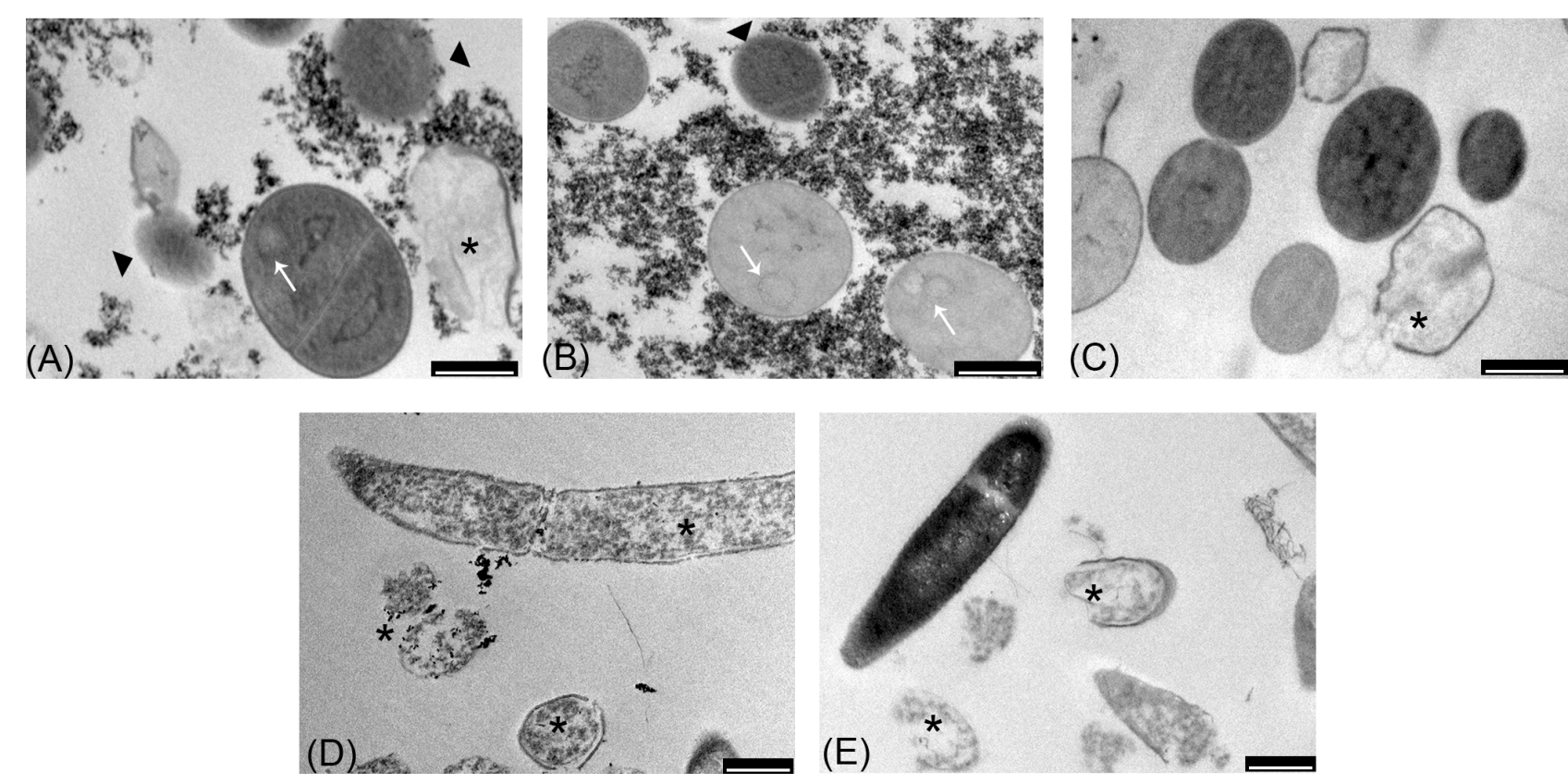

FIGURE 8 | TEM images of S. aureus ATCC 6538P (A-C) exposed to NP-APTES (A), NP-TEICO (B), teicoplanin (C), and B. subtilis ATCC 6633 (D,E) exposed to NP-TEICO (D) and teicoplanin (E). Scale bar: $500 \mathrm{~nm}$. -indicates ghost cells; *indicates lysed cells; white arrows indicate mesosome-like structures.

Huang et al., 2010; Ebrahiminezhad et al., 2014; Arakha et al., 2015a; Dinali et al., 2017).

\section{Effect of NPs on S. aureus Biofilm}

Because of the clinical relevance of biofilm infections, the effect of our NP preparations was tested on S. aureus ATCC 6538P biofilm formation and eradication. As shown in Figure 9A, non-conjugated teicoplanin and nanoconjugated teicoplanin inhibited significantly the biofilm formation at a concentration of $2.5 \mu \mathrm{g} / \mathrm{mL}\left(p=8.03 \times 10^{-5}\right)$ and $5 \mu \mathrm{g} / \mathrm{mL}(p=0.002)$, respectively. No inhibitory effect on biofilm formation was observed after adding IONPs or NP-APTES in comparison to the untreated condition. In the same experimental setting, investigating the effect of IONPs, NP-APTES, NP-TEICO, and teicoplanin on the bacterial viability of adherent and planktonic cell subpopulations gave further information. It was confirmed that IONPs and NP-APTES did not influence the viability of the two subpopulations. Conversely, nanoconjugated and nonconjugated teicoplanin inhibited in a dose-dependent manner the cell viability of both planktonic (Figure 9B) and adherent (Figure 9C) cells. Teicoplanin at $5 \mu \mathrm{g} / \mathrm{mL}$ caused the decrease of approximately $5 \mathrm{log}$ units in the survival of planktonic cells in comparison to the untreated control cells, whereas the NP-TEICO addition showed a comparable antimicrobial effect at the highest tested concentration of nanoconjugated teicoplanin corresponding to $10 \mu \mathrm{g} / \mathrm{mL}$ (Figure 9B). Increasing concentrations of non-conjugated teicoplanin caused a reduction of 2-3 log units in the survival of adherent cells, whereas, notably, the effect of nanoconjugated teicoplanin toward adherent cells was more pronounced (a reduction of $5 \log$ units) than that of non-conjugated teicoplanin at $10 \mu \mathrm{g} / \mathrm{mL}$ and it was statistically significant $(p=0.010)$ (Figure 9C). Conversely, neither nonconjugated teicoplanin nor nanoconjugated teicoplanin showed any dispersal effect on 48-h-old biofilms (data not shown), as expected, taking into account that this glycopeptide antibiotic inhibits cell wall synthesis in exponentially growing bacterial cells and is not active on bacterial cells entering into the stationary phase (Binda et al., 2014; Marcone et al., 2018).

\section{Cytotoxicity of NP-TEICO}

Cytotoxicity of NP-TEICO was evaluated using two different human cell lines, the well-established immortalized tumor cell line (SKOV-3) (Cappellini et al., 2015) and primary mesenchymal stem cells extracted from human adipose tissue, which are particularly sensitive to nanomaterials (Palombella et al., 2017). Results shown in Figure 10 indicate that teicoplanin did not exert any effect on the cell viability of either of the human cell lines at any of the tested concentrations. Conversely, both SKOV-3 cells and hASC responded to the exposure of IONPs and NP-TEICO in a concentration-dependent manner. No significant decrease in cell viability was observed after adding nanoconjugated teicoplanin in the range of teicoplanin antibacterial MICs $(0.78 \mu \mathrm{g} / \mathrm{mL})$ (Figures 10A,B). The corresponding amounts of carrying NPs did not influence cell viability significantly (Figures 10A,B). At a concentration threefold higher than the antibacterial MICs of NP-TEICO $(6 \mu \mathrm{g} / \mathrm{mL})$, the effects of nanoconjugated teicoplanin and of the carrier NPs significantly differed from that of the free antibiotic. Naked IONPs reduced cell viability by more than $60 \%$ (after $24 \mathrm{~h}$ of exposure) to $50 \%$ (after $96 \mathrm{~h}$ ) in SKOV-3 cells (Figure 10C), and by 50\% (after $24 \mathrm{~h}$ ) to $70 \%$ (after $96 \mathrm{~h}$ ) in hASC (Figure 10D). NP-TEICO were less cytotoxic, reducing cell viability by $40 \%$ (after $24 \mathrm{~h}$ ) to $20 \%$ (after 
A



B

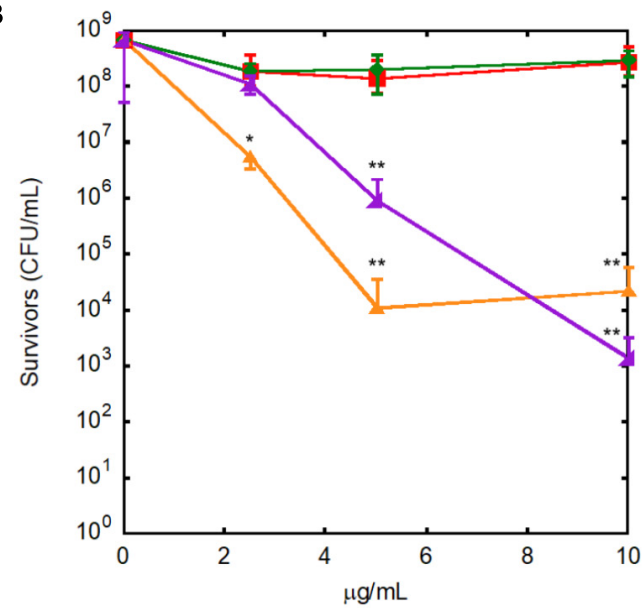

C

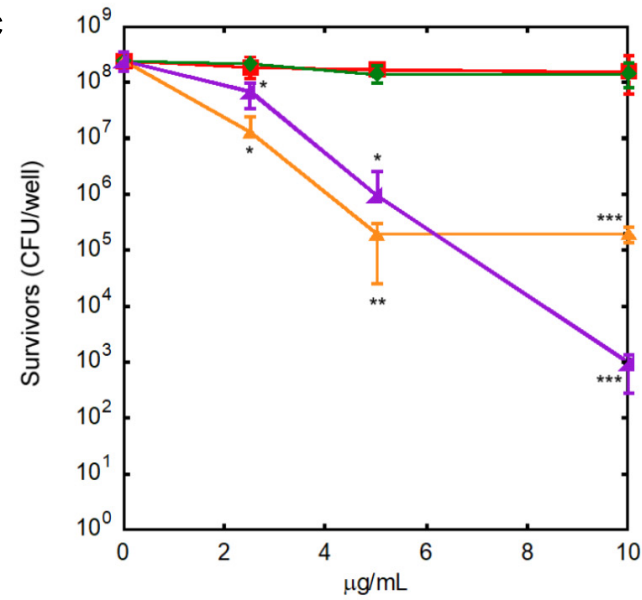

FIGURE 9 | Effect of increasing concentrations of teicoplanin, NP-TEICO, IONPS, and NP-APTES on S. aureus ATCC 6538P biofilm formation. In the case of NP preparations, the amounts to be added were defined considering the teicoplanin loaded on IONPs under the conditions defined in the Materials and Methods. Effect on adherent biomass following crystal violet staining (A). Effect on planktonic (B) and adherent (C) cells exposed to teicoplanin (orange), IONPs (red), NP-APTES (green), and NP-TEICO (violet) on viability assay. The values are expressed as mean $\pm \mathrm{SD}$ of three independent experiments. One-way ANOVA analyses, ${ }^{*} p<0.05,{ }^{* *} p<0.01$, and $* * * p<0.0001$
$96 \mathrm{~h}$ ) in SKOV-3 cells (Figure 10C) and by less than 30\% (after $24 \mathrm{~h}$ ) to $20 \%$ (after $96 \mathrm{~h}$ ) in hASC (Figure 10D). Interestingly, conjugation of antibiotic molecules to IONPs surface tended to reduce their intrinsic cytotoxicity, as already reported by other authors who demonstrated that covering the NP surface shields toxicity and improves biocompatibility (Javed et al., 2017; Xiang et al., 2017; Xie et al., 2017, 2018).

\section{DISCUSSION}

In the era of antibiotic resistance, the lipoglycopeptide teicoplanin is an extremely important antibiotic used for the prophylaxis and treatment of serious infections caused by Gram-positive bacteria, including MRSA and E. faecalis (Van Bambeke, 2006; Marcone et al., 2018). It is used to treat endocarditis, bacteremia, and bone and joint infections. Because of its efficacy and safety, it is used in pediatrics, too. Its spectrum of antibacterial action is similar to that of the previously discovered glycopeptide vancomycin, but teicoplanin has several advantages over vancomycin in the treatment of serious infections: longer half-life, lower nephrotoxicity and ototoxicity, and lack of requirement for serum assays in treated patients. Because of its better stability in vivo, it can be administered once a day or with an alternate daily dosage and by intravenous bolus or by intramuscular injection. Oral administration of teicoplanin has also been demonstrated to be effective in the treatment of pseudomembranous colitis and C. difficile-associated diarrhea. In addition, teicoplanin is active on some of the vancomycin-resistant enterococci, which are increasingly spreading in hospitals (Binda et al., 2014).

Notwithstanding these important features, to the best of our knowledge, this is the first report of using teicoplanin to functionalize NPs. The teicoplanin molecule has an addressable functional group (the $\mathrm{N}$-terminal carboxylic group of the heptapeptide chain) that we used to covalently bind the aminoactivated IONPs. Although there are few published data on optimizing the fabrication of nanoconjugated antibiotics onto IONPs (Lin et al., 2005; Hussein-Al-Ali et al., 2014; Zhu et al., 2015; Dinali et al., 2017), we succeeded in anchoring more than $100 \mu \mathrm{g}$ of teicoplanin per mg of NP-APTES in this work. The antimicrobial potency of nanoconjugated teicoplanin was slightly lower than that of the non-conjugated counterpart, particularly toward resistant clinical isolates, but NP-TEICO conserved the teicoplanin antimicrobial spectrum of activity toward Grampositive bacteria and it was particularly active in controlling S. aureus biofilm formation. The external membrane of Gramnegative bacteria covering the peptidoglycan layer remained highly impenetrable to both NP-TEICO and teicoplanin, impeding their interaction with the molecular target (Binda et al., 2014). One of the positive features of NP-TEICO prepared in this way was that the formulation maintained chemical stability and antimicrobial activity for at least 1 month. This aspect is relevant, considering that one main advantage of using magnetic antibiotic nanocarriers in vivo could be that they can be recovered and recycled after single uses, reducing local dose administration and potential side effects and decreasing the risk of selective 

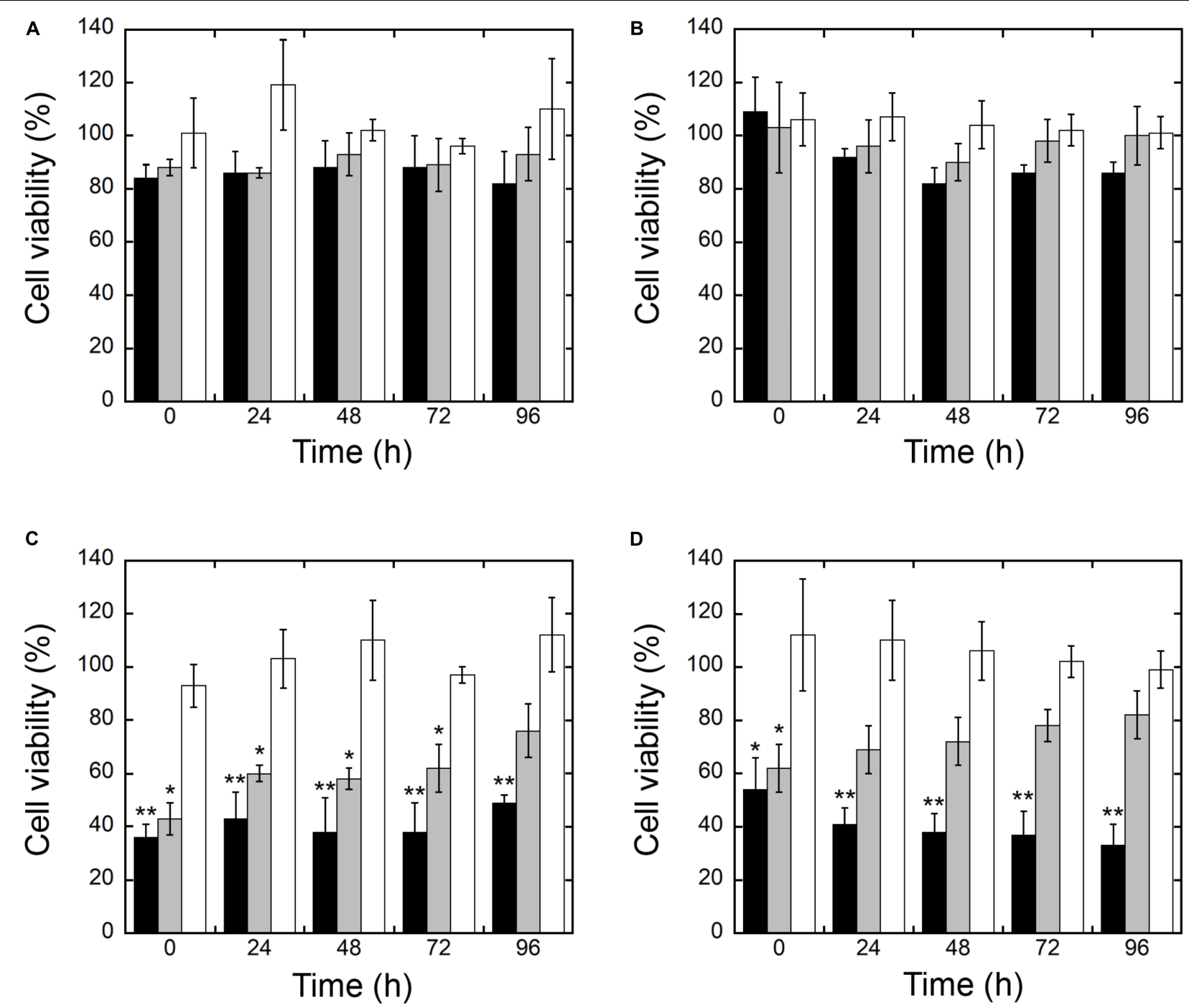

FIGURE 10 | Cell viability of SKOV 3 (A,C) and hASC (B,D) after different times of exposure to IONPs (black), NP-TEICO (gray), and teicoplanin (white). Cell viability is expressed as a percentage of viable cells compared to the untreated sample, set as $100 \%$. Here, $0.78 \mu \mathrm{g} / \mathrm{mL}$ of non-conjugated or nanoconjugated teicoplanin or $6.24 \mu \mathrm{g} / \mathrm{mL}$ of carrying NPs were added in (A,B); $6 \mu \mathrm{g} / \mathrm{mL}$ of non-conjugated or nanoconjugated teicoplanin or $48 \mu \mathrm{g} / \mathrm{mL}$ of carrying NPs were added in (C,D). In the case of NP preparations, the amounts to be added were defined considering the teicoplanin loaded on IONPs under the conditions defined in the Materials and Methods. The values are expressed as mean $\pm \mathrm{SD}$ of three independent experiments. One-way ANOVA analyses, ${ }^{*} p<0.05$ and ${ }^{* *} p<0.01$.

pressure on resistant strains. In addition, their targeted delivery to the site of infection/biofilm by using an external magnetic field might increase their in situ concentration, potentiating their local efficacy. For this reason, we consider the fact that NP-TEICO inhibited $S$. aureus biofilm formation, conserving the activity of non-conjugated teicoplanin versus the planktonic cells and improving it toward the adherent cells, to be promising. Different non-specific interactions such as electrostatic, hydrophobic, and van der Waal interactions are responsible for adhesion of bacteria on any material surfaces creating biofilms. Thus, it is possible that NP-TEICO anti-biofilm activity is potentiated (in comparison to the non-conjugated antibiotic) by intercepting these non-specific interactions, although in our experiments IONPs and NP-APTES had no effect on biofilm formation.
Unfortunately, $S$. aureus has dramatically re-emerged as a clinically relevant pathogen due to its resistance to antibiotics and the increased use of indwelling clinical devices. Millions of indwelling medical devices are implanted every year, and $S$. aureus is the major culprit for infections and failure of these devices (Arciola et al., 2018). S. aureus biofilms are also implicated in chronic wound infections such as diabetic foot ulcers, venous stasis ulcers, and pressure sores, which are quite resistant to antibiotic treatments. Teicoplanin carried by magnetically driven NPs can more easily reach deep tissue infections, which are difficult to treat using topical antibiotics due to the poor tissue penetration, and better penetrate the diffusion barriers that biofilms produce. 
In the last decade, a certain level of intrinsic antimicrobial and cytotoxicity activity has been controversially attributed to the IONPs themselves. Although IONPs and NP-APTES have shown some antibacterial effect against diverse Gram-positive and Gram-negative bacteria, the real extent of this phenomenon and the underlying mechanism has hitherto not been well understood (Baranwal et al., 2018). Ansari et al. (2017) reported a dose-dependent antibacterial activity of IONPs against Bacillus cereus and Klebsiella pneumoniae. In contrast, Auffan et al. (2008) indicated that chemically stable IONPs were not toxic to E. coli at $700 \mathrm{mg} / \mathrm{L}$, whereas Chatterjee et al. (2011) reported a dosedependent effect on E. coli cells. Borcherding et al. (2014) showed that IONPs had a positive effect in promoting the growth of Pseudomonas aeruginosa. Arakha et al. (2015a) published an illuminating study and demonstrated, by combining a complete set of microbiological and biophysical methods, that IONPs did not show any significant antimicrobial activity toward B. subtilis and E. coli. Coating IONPs with positively charged chitosan, instead, conferred them with an increased so-called antimicrobial propensity against $B$. subtilis and $E$. coli, which depends on the interfacial interaction between NPs and bacterial surfaces (Arakha et al., 2015a,b).

In the present work, we compared the antimicrobial activity of NP-TEICO with that shown by IONPs and NP-APTES by using a set of methods (agar diffusion assay, BacLight fluorescence assay, bacterial growth kinetics, CFU measurement, and TEM observations) comparable to those previously used by Arakha et al. (2015a,b). Thus, we could conclude that the antibiotic activity of nanoconjugated and non-conjugated teicoplanin differed dramatically from the phenomenon described as antimicrobial propensity, which is based on an electrostatic attraction between cationic NPs and anionic bacterial cell surfaces (Arakha et al., 2015a,b). Electrostatic attraction promotes unspecific adhesion of NPs onto the cell wall of Gram-positive bacteria and the external cell membrane of the Gram-negative bacteria (Qi et al., 2013; Baranwal et al., 2018). This adhesion likely represents the mechanism by which IONPs and, to a greater extent, the positively charged NP-APTES impaired the growth of $S$. aureus, B. subtilis, and E. coli in our experiments of bacterial growth kinetics. This interfacial effect was transient and reversible, differing from the specific killing activity of teicoplanin and NP-TEICO toward the Gram-positive bacteria. Nevertheless, TEM observations suggested that we cannot completely rule out that cell adhesion of IONPs and of NP-APTES might provoke cytosolic shrinkage and cell membrane detachment (and eventually cell rupture), as observed in S. aureus and, with a lower frequency, in B. subtilis. In any case, this phenomenon was again sporadic, probably depending on surface composition and on the physiological state of single bacterial cells, as indicated by Dinali et al. (2017).

Although IONPs have been increasingly proposed for a wide range of biomedical applications, such as drug delivery, magnetic resonance imaging, thermal ablation therapy, and treatment of iron-deficient anemia, our understanding of their interaction with animal cells and animal models is still relatively limited (Natan and Banin, 2017; Feng et al., 2018). Recent studies showed that physicochemical properties, including particle size, PDI, surface charge, oxidation state of iron, and different surface coatings, greatly influence their biological effect in vitro and in vivo (Feng et al., 2018; Wang et al., 2018). Among the super magnetic NPs, IONPs were generally preferred because they are less toxic than those based on nickel and cobalt (Gornati et al., 2016). However, it was recently demonstrated that IONPs can enter eukaryotic cells not only by endocytosis, but also by diffusion through the plasma membrane, gaining direct access to the cytoplasm (Zanella et al., 2017). In addition, the intrinsic catalase-like activity of IONPs might antagonize the accumulation of toxic reactive oxygen species they have induced and thereby modulate the extent of cellular oxidative stress, autophagic activity, and programmed cell death (Wang et al., 2018). In this complex framework, a complete evaluation of the cytocompatibility of our NP-TEICO preparation in vitro and in vivo systems lies outside the scope of this work, although it would represent a future interesting extension of the study. Here, we demonstrated that at the concentrations that encompass the teicoplanin antibacterial MIC values, teicoplanin coating of IONPs reduced their intrinsic cytotoxicity toward two human cell lines, thus improving their potential biocompatibility. Further intensive in vitro and in vivo investigations are needed to develop an NP-TEICO-based drug formulation that could be administered systemically or topically to treat deep tissue infections and/or cover medical devices to prevent biofilm formation. Our results indicate that combining synergistically the unique properties of different nanomaterials would represent a good strategy, in this way providing a novel route to prevent and treat bacterial infections and, at the same time, reduce the intrinsic cytotoxicity of NPs, as already indicated by other authors (Xiang et al., 2017; Xie et al., 2017, 2018).

\section{AUTHOR CONTRIBUTIONS}

IA, GM, GB, and FM conceived the experiments, interpreted the results, and wrote the manuscript. IA developed and produced the NPs and performed the characterization. IA, FB, and GM conducted and interpreted the experiments on the microbiological activity of NPs. VO and EM conducted and analyzed the experiments on biofilms. CP and RG performed the microscopical observations and cell cytotoxicity tests and analyzed the results. All authors reviewed and approved the final manuscript.

\section{FUNDING}

This work was supported by public grants "Fondo di Ateneo per la Ricerca" 2016, 2017 to FM, GM, RG, and GB.

\section{ACKNOWLEDGMENTS}

We are grateful to Consorzio Interuniversitario per le Biotecnologie for supporting congress participation of FB. IA is a Ph.D. student of the "Biotechnology, Biosciences and Surgical Technology” course at Università degli Studi dell'Insubria. EM is a Ph.D. student of the "Life Science and Biotechnology" course at Università degli Studi dell'Insubria. 


\section{REFERENCES}

Ali, A., Zafar, H., Zia, M., ul Haq, I., Phull, A. R., Ali, J. S., et al. (2016). Synthesis, characterization, applications, and challenges of iron oxide nanoparticles. Nanotechnol. Sci. Appl. 9, 49-67. doi: 10.2147/NSA.S99986

Allen, N. E., and Nicas, T. I. (2003). Mechanism of action of oritavancin and related glycopeptide antibiotics. FEMS Microbiol. Rev. 26, 511-532. doi: 10. 1111/j.1574-6976.2003.tb00628.x

Ansari, S. A., Oves, M., Satar, R., Khan, A., Ahmad, S. I., Jafri, M. A., et al. (2017). Antibacterial activity of iron oxide nanoparticles synthesized by coprecipitation technology against Bacillus cereus and Klebsiella pneumoniae. Polish J. Chem. Technol. 4, 110-115. doi: 10.1515/pjct-2017-0076

Arakha, M., Pal, S., Samantarrai, D., Panigrahi, T. K., Mallick, B. C., Pramanik, K., et al. (2015a). Antimicrobial activity of iron oxide nanoparticle upon modulation of nanoparticle-bacteria interface. Sci. Rep. 5:14813. doi: 10.1038/ srep 14813

Arakha, M., Saleem, M., Mallick, B. C., and Jha, S. (2015b). The effects of interfacial potential on antimicrobial propensity of $\mathrm{ZnO}$ nanoparticle. Sci. Rep. 5:9578. doi: $10.1038 /$ srep09578

Arciola, C. R., Campoccia, D., and Montanaro, L. (2018). Implant infections: adhesion, biofilm formation and immune evasion. Nat. Rev. Microbiol. 16, 397-409. doi: 10.1038/s41579-018-0019-y

Armenia, I., Balzaretti, R., Pirrone, C., Allegretti, C., D’Arrigo, P., Valentino, M., et al. (2017). L-aspartate oxidase magnetic nanoparticles: synthesis, characterization and L-aspartate bioconversion. RSC Adv. 7, 21136-21143. doi: 10.1039/C7RA00384F

Auffan, M., Achouak, W., Rose, J., Roncato, M. A., Chanéac, C., Waite, D. T., et al. (2008). Relation between the redox state of iron-based nanoparticles and their cytotoxicity toward Escherichia coli. Environ. Sci. Technol. 42, 6730-6735. doi: 10.1021/es800086f

Balzaretti, R., Meder, F., Monopoli, M. P., Boselli, L., Armenia, I., Pollegioni, L., et al. (2017). Synthesis, characterization and programmable toxicity of iron oxide nanoparticles conjugated with D-amino acid oxidase. RSC Adv. 7, 1439-1442. doi: 10.1039/c6ra25349k

Baranwal, A., Srivastava, A., Kumar, P., Bajpai, V. K., Maurya, P. K., and Chandra, P. (2018). Prospects of nanostructure materials and their composites as antimicrobial agents. Front. Microbiol. 9:422. doi: 10.3389/fmicb.2018. 00422

Binda, E., Cappelletti, P., Marinelli, F., and Marcone, G. L. (2018). Specificity of induction of glycopeptide antibiotic resistance in the producing actinomycetes. Antibiotics 7:E36. doi: 10.3390/antibiotics7020036

Binda, E., Marinelli, F., and Marcone, G. L. (2014). Old and new glycopeptide antibiotics: action and resistance. Antibiotics 3, 572-594. doi: 10.3390/ antibiotics 3040572

Borcherding, J., Baltrusaitis, J., Chen, H., Stebounova, L., Wu, C. M., Rubasinghege, G., et al. (2014). Iron oxide nanoparticles induce Pseudomonas aeruginosa growth, induce biofilm formation, and inhibit antimicrobial peptide function. Environ. Sci. Nano 1, 123-132. doi: 10.1039/C3EN00029J

Cappellini, F., Recordati, C., Maglie, M., De Pollegioni, L., Rossi, F., Daturi, M., et al. (2015). New synthesis and biodistribution of the D-amino acid oxidasemagnetic nanoparticle system. Future Sci. OA 1, FS067. doi: 10.4155/Fso. 15.67

Chakraborty, S. P., Sahu, S. K., Mahapatra, S. K., Santra, S., Bal, M., Roy, S., et al. (2010). Nanoconjugated vancomycin: new opportunities for the development of anti-VRSA agents. Nanotechnol. 21, 105103-105111. doi: 10.1088/0957-4484/ 21/10/105103

Chakraborty, S. P., Sahu, S. K., Pramanik, P., and Roy, S. (2012). In vitro antimicrobial activity of nanoconjugated vancomycin against drug resistant Staphylococcus aureus. Int. J. Pharm. 436, 659-676. doi: 10.1016/j.ijpharm.2012. 07.033

Chatterjee, S., Bandyopadhyay, A., and Sarkar, K. (2011). Effect of iron oxide and gold nanoparticles on bacterial growth leading towards biological application. J. Nanobiotechnol. 9, 34-40. doi: 10.1186/1477-3155-9-34

Chifiriuc, M. C., Grumezescu, A. M., Andronescu, E., Ficai, A., Cotar, A. I., Grumezescu, V., et al. (2013). Water dispersible magnetite nanoparticles influence the efficacy of antibiotics against planktonic and biofilm embedded
Enterococcus faecalis cells. Anaerobe 22, 14-19. doi: 10.1016/j.anaerobe.2013. 04.013

Chudasama, B., Vala, A. K., Andhariya, N., Upadhyay, R. V., and Mehta, R. V. (2009). Enhanced antibacterial activity of bifunctional Fe3O4-Ag core-shell nanostructures. Nano Res. 2, 955-965. doi: 10.1007/s12274-009-9098-4

CLSI (2018). Performance Standards for Antimicrobial Susceptibility Testing, 28th Edn. Wayne, PA: Clinical and Laboratory Standards Institute.

Davis, D. (2003). Understandng biofilm resistance to antibacterial agents. Nat. Rev. Drug Discov. 2, 114-122. doi: 10.1038/nrd1008

De Palma, R., Peeters, S., Van Bael, M. J., Van Den Rul, H., Bonroy, K., Laureyn, W., et al. (2007). Silane ligand exchange to make hydrophobic superparamagnetic nanoparticles water-dispersible. Chem. Mater. 19, 1821-1831. doi: 10.1021/ $\mathrm{cm} 0628000$

Dinali, R., Ebrahiminezhad, A., Manley-Harris, M., Ghasemi, Y., and Berenjian, A. (2017). Iron oxide nanoparticles in modern microbiology and biotechnology. Crit. Rev. Microbiol. 43, 493-507. doi: 10.1080/1040841X.2016.1267708

Dong, S. D., Oberthür, M., Losey, H. C., Anderson, J. W., Eggert, U. S., Peczuh, M. W., et al. (2002). The structural basis for induction of VanB resistance. J. Am. Chem. Soc. 124, 9064-9065. doi: 10.1021/ja026342h

Durán, N., Durán, M., de Jesus, M. B., Seabra, A. B., Fávaro, W. J., and Nakazato, G. (2016). Silver nanoparticles: a new view on mechanistic aspects on antimicrobial activity. Nanomedicine 12, 789-799. doi: 10.1016/j.nano.2015.11.01

Ebrahiminezhad, A., Rasoul-Amini, S., Davaran, S., Barar, J., and Ghasemi, Y. (2014). Impacts of iron oxide nanoparticles on the invasion power of Listeria monocytogenes. Curr. Nanosci. 10, 382-388. doi: 10.2174/ 15734137113096660109

El Zowalaty, M. E., Hussein-Al-Ali, S. H., Husseiny, M. I., Geilich, B. M., Webster, T. J., and Hussein, M. Z. (2015). The ability of streptomycin-loaded chitosancoated magnetic nanocomposites to possess antimicrobial and antituberculosis activities. Int. J. Nanomedicine 10, 3269-3274. doi: 10.2147/IJN.S7 4469

Fedorenko, V., Genilloud, O., Horbal, L., Marcone, G. L., Marinelli, F., Paitan, Y., et al. (2015). Antibacterial discovery and development: from gene to product and back. Biomed. Res. Int. 2015:591349. doi: 10.1155/2015/591349

Feng, Q., Liu, Y., Huang, J., Chen, K., Huang, J., and Xiao, K. (2018). Uptake, distribution, clearance, and toxicity of iron oxide nanoparticles with different sizes and coatings. Sci. Rep. 8:2082. doi: 10.1038/s41598-018-19628-z

Finn, R. K. (1959). Theory of agar diffusion methods for bioassay. Anal. Chem. 31, 975-977. doi: 10.1021/ac60150a040

Gonçalves, L. C., Seabra, A. B., Pelegrino, M. T., de Araujo, D. R., Bernardes, J. S., and Haddad, P. S. (2017). Superparamagnetic iron oxide nanoparticles dispersed in pluronic F127 hydrogel: potential uses in topical applications. RSC Adv. 7, 14496-14503. doi: 10.1039/C6RA28633J

Gornati, R., Pedretti, E., Rossi, F., Cappellini, F., Zanella, M., Olivato, I., et al. (2016). Fe, Co and Ni nanoparticle toxicity evaluated on SKOV-3 and U87 cell lines. J. Appl. Toxicol. 36, 385-393. doi: 10.1002/jat.3220

Grumezescu, A. M., Gesta, M. C., Holban, A. M., Grumezescu, V., Vasile, B. S., Mogoanta, L., et al. (2014). Biocompatible Fe3O4 increases the efficacy of amoxicillin delivery against Gram-positive and Gram-negative bacteria. Molecules 19, 5013-5027. doi: 10.3390/molecules19045013

Gu, H., Ho, P. L., Tsang, K. W. T., Yu, C. W., and Xu, B. (2003). Using biofunctional magnetic nanoparticles to capture Gram-negative bacteria at an ultra-low concentration. Chem. Commun. 7, 1966-1967. doi: 10.1039/ b305421g

Hajipour, M. J., Fromm, K. M., Akbar Ashkarran, A., Jimenez de Aberasturi, D., Larramendi, I. R., de Rojo, T., et al. (2012). Antibacterial properties of nanoparticles. Trends Biotechnol. 30, 499-511. doi: 10.1016/j.tibtech.2012. 06.004

Hartmann, M., Berditsch, M., Hawecker, J., Ardakani, M. F., Gerthsen, D., and Ulrich, A. S. (2010). Damage of the bacterial cell envelope by antimicrobial peptides gramicidin S and PGLa as revealed by transmission and scanning electron microscopy. Antimicrob. Agents Chemother. 54, 3132-3142. doi: 10. 1128/AAC.00124-10

Hermanson, G. T. (2013). "Zero-Length Crosslinkers," in Bioconjugate Techniques, 3rd Edn, eds J. Audet and M. Preap (London, UK: Academic Press), 259-268. doi: 10.1016/B978-0-12-382239-0.00004-2 
Huang, Y. F., Wang, Y. F., and Yan, X. P. (2010). Amine-functionalized magnetic nanoparticles for rapid capture and removal of bacterial pathogens. Environ. Sci. Technol. 44, 7908-7913. doi: 10.1021/es102285n

Hussein-Al-Ali, S. H., El Zowalaty, M. E., Hussein, M. Z., Geilich, B. M., and Webster, T. J. (2014). Synthesis, characterization, and antimicrobial activity of an ampicillin-conjugated magnetic nanoantibiotic for medical applications. Int. J. Nanomedicine 9, 3801-3814. doi: 10.2147/IJN.S61143

Javed, Y., Akhtar, K., Anwar, H., and Jamil, Y. (2017). MRI based on iron oxide nanoparticles contrast agents: effect of oxidation state and architecture. J. Nanopart. Res. 19:366. doi: 10.1007/s11051-017-4045-x

Kell, A. J., Stewart, G., Ryan, S., Peytavi, R., Boissinot, M., Huletsky, A., et al. (2008). Vancomycin-modified nanoparticles for efficient targeting and preconcentration of Gram-positive and Gram-negative bacteria. ACS 2, 1777-1788. doi: 10.1021/nn700183g

Lin, Y. S., Tsai, P. J., Weng, M. F., and Chen, Y. C. (2005). Affinity capture using vancomycin-bound magnetic nanoparticles for the MALDI-MS analysis of bacteria. Anal. Chem. 77, 1753-1760. doi: 10.1021/ac048990k

Marcone, G. L., Binda, E., Berini, F., and Marinelli, F. (2018). Old and new glycopeptide antibiotics: from product to gene and back in the post-genomic era. Biotechnol. Adv. 36, 534-554. doi: 10.1016/j.biotechadv.2018.02.009

May, J., Shannon, K., King, A., and French, G. (1998). Glycopeptide tolerance in Staphylococcus aureus. J. Antimicrob. Chemother. 42, 189-197. doi: 10.1093/jac/ 42.2.189

Natan, M., and Banin, E. (2017). From Nano to Micro: using nanotechnology to combat microorganisms and their multidrug resistance. FEMS Microbiol. Rev. 41, 302-322. doi: 10.1093/femsre/fux003

Palombella, S., Pirrone, C., Rossi, F., Armenia, I., Cherubino, M., Valdatta, L., et al. (2017). Effects of metal micro and nano-particles on hASCs: an in vitro model. Nanomaterials 7:E212. doi: 10.3390/nano7080212

Qi, G., Li, L., Yu, F., and Wang, H. (2013). Vancomycin-modified mesoporous silica nanoparticles for selective recognition and killing of pathogenic Grampositive bacteria over macrophage-like cells. ACS Appl. Mater. Interfaces 5, 10874-10881. doi: 10.1021/am403940d

Schneider, C. A., Rasband, W. S., and Eliceiri, K. W. (2012). NIH Image to ImageJ: 25 years of image analysis. Nat. Methods 9, 671-675.

Shimoda, M., Ohki, K., Shimamoto, Y., and Kohashi, O. (1995). Morphology of defensin-treated Staphylococcus aureus. Infect. Immun. 63, 2886-2891.

Stepien, G., Moros, M., Pérez-Hernández, M., Monge, M., Gutiérrez, L., Fratila, R. M., et al. (2018). Effect of surface chemistry and associated protein corona on the long-term biodegradation of iron oxide nanoparticles in vivo. ACS Appl. Mater. Interfaces 10, 4548-4560. doi: 10.1021/acsami.7b18648

Szpak, A., Kania, G., Skórka, T., Tokarz, W., Zapotoczny, S., and Nowakowska, M. (2013). Stable aqueous dispersion of superparamagnetic iron oxide nanoparticles protected by charged chitosan derivatives. J. Nanoparticle Res. 15, 1372-1382. doi: 10.1007/s11051-012-1372-9

Taurino, C., Frattini, L., Marcone, G. L., Gastaldo, L., and Marinelli, F. (2011). Actinoplanes teichomyceticus ATCC 31121 as a cell factory for producing teicoplanin. Microb. Cell Fact. 10, 82-94. doi: 10.1186/1475-2859$10-82$

Tran, N., Mir, A., Mallik, D., Sinha, A., Nayar, S., and Webster, T. J. (2010). Bactericidal effect of iron oxide nanoparticles on Staphylococcus aureus. Int. J. Nanomedicine 5, 277-283. doi: 10.2147/IJN.S9220

Treviño, J., Bayón, C., Ardá, A., Marinelli, F., Gandolfi, R., Molinari, F., et al. (2014). New insights into glycopeptide antibiotic binding to cell wall precursors using SPR and NMR spectroscopy. Chemistry 20, 7363-7372. doi: 10.1002/ chem. 201303310
Van Bambeke, F. (2006). Glycopeptides and glycodepsipeptides in clinical development: a comparative review of their antibacterial spectrum, pharmacokinetics and clinical efficacy. Curr. Opin. Investig. Drug 7, 740-749.

Venkatesan, N., Perumal, G., and Doble, M. (2015). Bacterial resistance in biofilmassociated bacteria. Future Microbiol. 10, 1743-1750. doi: 10.2217/fmb.15.69

Wang, C., Zhang, K., Zhou, Z., Li, Q., Shao, L., Hao, R. Z., et al. (2017). Vancomycin-modified Fe3O4@SiO2@Ag microflowers as effective antimicrobial agents. Int. J. Nanomedicine 12, 3077-3094.

Wang, L., Wang, Z., Li, X., Zhang, Y., Yin, M., Li, J., et al. (2018). Deciphering active biocompatibility of iron oxide nanoparticles from their intrinsic antagonism. Nano Res. 11, 2746-2755. doi: 10.1007/s12274-017-1905-8

Weiner, L. M., Webb, A. K., Limbago, B., Dudeck, M. A., Patel, J., Kallen, A. J., et al. (2016). Antimicrobial-resistant pathogens associated with healthcareassociated infections: summary of data reported to the National Healthcare Safety Network at the Centers for Disease Control and Prevention, 20112014. Infect. Control Hosp. Epidemiol. 37, 1288-1301. doi: 10.1017/ice. 2016.174

WHO (2017). Antibacterial Agents in Clinical Development: an Analysis of the Antibacterial Clinical Development Pipeline, Including Tuberculosis. Geneva: World Health Organization.

Wu, W., Wu, Z., Yu, T., Jiang, C., and Kim, W. S. (2015). Recent progress on magnetic iron oxide nanoparticles: synthesis, surface functional strategies and biomedical applications. Sci. Technol. Adv. Mater. 16:023501. doi: 10.1088/ 1468-6996/16/2/023501

Xiang, Y., Li, J., Liu, X., Cui, Z., Yang, X., Yeung, K. W. K., et al. (2017). Construction of poly(lactic-co-glycolic acid)/ZnO nanorods/Ag nanoparticles hybrid coating on $\mathrm{Ti}$ implants for enhanced antibacterial activity and biocompatibility. Mater. Sci. Eng. C 79, 629-637. doi: 10.1016/j.msec.2017. 05.115

Xie, X., Mao, C., Liu, X., Tan, L., Cui, Z., Yang, X., et al. (2018). Tuning the bandgap of photo-sensitive polydopamine/Ag3PO4/graphene oxide coating for rapid, noninvasive disinfection of implants. ACS Cent. Sci. 4, 724-738. doi: 10.1021/acscentsci.8b00177

Xie, X., Mao, C., Liu, X., Zhang, Y., Cui, Z., Yang, X., et al. (2017). Synergistic bacteria killing through photodynamic and physical actions of graphene oxide/Ag/collagen coating. ACS Appl. Mater. Interfaces 9, 26417-26428. doi: 10.1021/acsami.7b06702

Zanella, D., Bossi, E., Gornati, R., Bastos, C., Faria, N., and Bernardini, G. (2017). Iron oxide nanoparticles can cross plasma membranes. Sci. Rep. 7:11413. doi: 10.1038/s41598-017-11535-Z

Zhu, M., Liu, W., Liu, H., Liao, Y., Wei, J., Zhou, X., et al. (2015). Construction of Fe3O4/vancomycin/PEG magnetic nanocarrier for highly efficient pathogen enrichment and gene sensing. ACS Appl. Mater. Interfaces 7, 12873-12881. doi: $10.1021 /$ acsami.5b02374

Conflict of Interest Statement: The authors declare that the research was conducted in the absence of any commercial or financial relationships that could be construed as a potential conflict of interest.

Copyright (c) 2018 Armenia, Marcone, Berini, Orlandi, Pirrone, Martegani, Gornati, Bernardini and Marinelli. This is an open-access article distributed under the terms of the Creative Commons Attribution License (CC BY). The use, distribution or reproduction in other forums is permitted, provided the original author(s) and the copyright owner(s) are credited and that the original publication in this journal is cited, in accordance with accepted academic practice. No use, distribution or reproduction is permitted which does not comply with these terms. 